\title{
Multi-Level Evaluation of UV Action upon Vitamin D Enhanced, Silver Doped Hydroxyapatite Thin Films Deposited on Titanium Substrate
}

\author{
Catalin Constantin Negrila ${ }^{1}$, Daniela Predoi ${ }^{1, *}$, Rodica V. Ghita ${ }^{1}$, Simona Liliana Iconaru ${ }^{1, *}$, \\ Steluta Carmen Ciobanu ${ }^{1}$, Mirela Manea ${ }^{2}$, Monica Luminita Badea 1,3, Adrian Costescu ${ }^{4}$, Roxana Trusca ${ }^{5}$, \\ Gabriel Predoi ${ }^{6}$, George A. Stanciu ${ }^{7}$ D, Radu Hristu ${ }^{7}$, Laura Denisa Dragu ${ }^{8,9}$, Coralia Bleotu ${ }^{8,9,10}$ (D), \\ Andreea Groza ${ }^{11}$, Ioana Cristina Marinas ${ }^{9}$ iD and Mariana Carmen Chifiriuc $9,10,12, *$ (D)
}

Citation: Negrila, C.C.; Predoi, D.; Ghita, R.V.; Iconaru, S.L.; Ciobanu, S.C.; Manea, M.; Badea, M.L.; Costescu, A.; Trusca, R.; Predoi, G.; et al. Multi-Level Evaluation of UV Action upon Vitamin D Enhanced, Silver Doped Hydroxyapatite Thin Films Deposited on Titanium Substrate. Coatings 2021, 11, 120. https://doi.org/10.3390/ coatings 11020120

Academic Editor: Sergey Dorozhkin Received: 14 December 2020

Accepted: 15 January 2021

Published: 21 January 202

Publisher's Note: MDPI stays neutra with regard to jurisdictional claims in published maps and institutional affiliations.

Copyright: (c) 2021 by the authors. Licensee MDPI, Basel, Switzerland This article is an open access article distributed under the terms and conditions of the Creative Commons Attribution (CC BY) license (https:// creativecommons.org/licenses/by/ $4.0 /)$
1 Multifunctional Materials and Structures Laboratory, National Institute of Materials Physics, Atomistilor Street, No. 405A, P.O. Box MG 07, 077125 Magurele, Romania; catalin.negrila@infim.ro (C.C.N.); ghitar@infim.ro (R.V.G.); ciobanucs@gmail.com (S.C.C.); badea.artemisia@gmail.com (M.L.B.)

2 Department of Surgery, Carol Davila University of Medicine and Pharmacy, 8 Eroii Sanitari, Sector 5, 050474 Bucharest, Romania; mirelamanea2003@yahoo.com

3 Faculty of Horticulture, University of Agronomic Sciences and Veterinary Medicine, 59 Marasti Blvd., 011464 Bucharest, Romania

4 Faculty of Exact Sciences \& Engineering, Hyperion University of Bucharest, 169 Calea Călărași, 030615 Bucharest, Romania; adrian.costescu@gmail.com

5 National Centre for Micro and Nanomaterials, University Politehnica of Bucharest, 060042 Bucharest, Romania; truscaroxana@yahoo.com

6 Faculty of Veterinary Medicine, University of Agronomic Sciences and Veterinary Medicine of Bucharest, 105 Splaiul Independentei, Sector 5, 050097 Bucharest, Romania; gabrielpredoi2017@gmail.com

7 Center for Microscopy-Microanalysis and Information Processing, University Politehnica of Bucharest, 313 Splaiul Independentei, 060042 Bucharest, Romania; stanciu@physics.pub.ro (G.A.S.); radu.hristu@physics.pub.ro (R.H.)

8 "Stefan S Nicolau" Institute of Virology, Romanian Academy, 030304 Bucharest, Romania; denisa_dragu81@yahoo.com (L.D.D.); cbleotu@yahoo.com (C.B.)

9 Life, Environmental and Earth Sciences Division, Research Institute of the University of Bucharest (ICUB), University of Bucharest, 060023 Bucharest, Romania; ioana.cristina.marinas@gmail.com

10 Microbiology Department, Faculty of Biology, University of Bucharest, 1-3 Portocalelor Lane, 77206 Bucharest, Romania

11 Plasma and Radiation Physics, National Institute for Laser, 409 Atomistilor Street, P.O. Box MG 36, 077125 Magurele, Romania; andreeagroza75@gmail.com

12 Academy of Romanian Scientists, Ilfov Street, No. 3, 010164 Bucharest, Romania

* Correspondence: dpredoi@gmail.com (D.P.); simonaiconaru@gmail.com (S.L.I.); carmen.chifiriuc@gmail.com (M.C.C.)

\begin{abstract}
Hydroxyapatite $\mathrm{Ca}_{10}\left(\mathrm{PO}_{4}\right)_{6}(\mathrm{OH})_{2}(\mathrm{HAp})$ is an important bioactive material for bone tissue reconstruction, due to its highly thermodynamic stability at a physiological $\mathrm{pH}$ without bio-resorption. In the present study, the Ag:HAp and the corresponding Ag:HAp + D3 thin films ( 200 nm) coating were obtained by vacuum deposition method on Ti substrate. The obtained samples were exposed to different UV irradiation times, in order to investigate the UV light action upon thin films, before considering this method for the thin film's decontamination. The effects of UV irradiation upon Ag:Hap + D3 are presented for the first time in the literature, marking a turning point for understanding the effect of UV light on composite biomaterial thin films. The UV irradiation induced an increase in the initial stages of surface roughness of Ag:HAp thin film, correlated with the modifications of XPS and FTIR signals. The characteristics of thin films measured by AFM (RMS) analysis corroborated with XPS and FTIR investigation highlighted a process of recovery of the thin film's properties (e.g., RMS), suggesting a possible adaptation to UV irradiation. This process has been a stage to a more complicated UVA rapid degradation process. The antifungal assays demonstrated that all the investigated samples exhibited antifungal properties. Moreover, the cytotoxicity assays revealed that the HeLa cells morphology did not show any alterations after $24 \mathrm{~h}$ of incubation with the Ag:HAp and Ag:HAp + D3 thin films.
\end{abstract}


Keywords: hydroxyapatite; thin films; biomaterial; ultraviolet irradiation

\section{Introduction}

Hydroxyapatite $\mathrm{Ca}_{10}\left(\mathrm{PO}_{4}\right)_{6}(\mathrm{OH})_{2}$, and (HAp), is an important compound with remarkable biological properties, mainly used in the biomedical field, as a bioactive material for bone tissue reconstruction, due to its highly thermodynamically stability at a physiological $\mathrm{pH}$ (i.e., 7.4), but without bio-resorption [1]. Due to its good biocompatibility HAp has been used on dental and orthopedic implants to promote the growth of natural bone into prosthetic devices [2,3]. The advantage of using HAp as bio implant coating is related to its capability to connect structurally and functionally with the human bone, increasing the osteo-inductivity of medical devices [4]. However, these biomaterials can be also used for the decontamination of polluted water $[5,6]$. An important effort was dedicated to the deposition of HAp on corrosion resistant alloys, where the relative thickness of HAp films in the range 10 200 $\mu \mathrm{m}$ have risen different problems as exfoliation, interior cracking of the coating layer or the difficulty of deposition on porous materials, such as semiconductors (e.g., Si (100)) for bio-electronic hybrid-layered structures. In order to improve the biological properties of hydroxyapatite-based biomaterials they are enriched with various ions/compounds [6-11]. Silver provides advantageous biochemical inertness and presents a broad spectrum of antibacterial activity $[12,13]$. Thus, the silver doped HAp (AgHAp) exhibits a dual property, i.e., bacterial inhibition and the enhancement of implant osteo-conductivity [14].

One of the most known fat-soluble vitamin is vitamin $\mathrm{D}$ which is generally found in products of animal origin [15]. Also, vitamin D plays a key role in regulating the concentration of calcium and phosphorus in the blood [15,16]. Moreover, it has an essential role in bone metabolism participating in various processes such as osteoblast differentiation, proliferation, and apoptosis $[15,16]$. Previous studies have reported that vitamin D possess antioxidant and anti-inflammatory properties and it is also involved in T cell-mediated immunity $[17,18]$. According to the in vitro study reported by Ambrożewicz, E., et al. [18] the presence of various vitamins $(\mathrm{D}, \mathrm{K})$ in the HAp matrix could reduce the side effects of biomaterials on osteoblasts growth [18]. The ultraviolet radiation is generally used as a surface decontamination method, but it has ben also proposed for the first time to be used for modifying the HAp surfaces in order to improve the in vitro response of osteoblast-like cells [19].

In the present study, the Ag:HAp and Ag:HAp + D3 thin films $(\sim 200 \mathrm{~nm})$ coating were obtained by the classical vacuum deposition method on Ti substrate. The different samples were exposed to different UV irradiation times, in order to understand the action of UV light upon thin films, as a possible biological effect following the UV decontamination. The effect of UV irradiance upon Ag:Hap + D3 marks a turning point in understanding the effect of UV light on composite thin films and is reported for the first time in this study. We present the composition, morphology, structure of composite films, as well as the biological effect on different cell cultures. From this point of view our study opens an avenue towards understanding the behavior of Ag:HAp thin films in UVA light.

\section{Materials and Methods}

\subsection{Sample Preparation}

The first stage in the preparation of $\mathrm{Ag}$ doped HAp powder consisted in the synthesis from: Ammonium dihydrogen phosphate: $\left(\mathrm{NH}_{4}\right)_{2} \mathrm{HPO}_{4}$, calcium nitrate: $\mathrm{Ca}\left(\mathrm{NO}_{3}\right)_{2} \cdot 4 \mathrm{H}_{2} \mathrm{O}$, and silver nitrate: $\mathrm{AgNO}_{3}$ all of them commercially available (Alpha Aesare). The method used for preparation was co-precipitation [8], where the characteristics of mixed solution where Ca/P molar ratio: 1.67, and Ag:HAp $\left(\mathrm{Ca}_{1-\mathrm{x}} \mathrm{Ag}_{\mathrm{x}}\left(\mathrm{PO}_{4}\right)_{6}(\mathrm{OH})_{2}\right.$ with $\mathrm{x}_{\mathrm{Ag}}=0.5$. The $\mathrm{Ca}$ and $\mathrm{Ag}$ containing solution was stirred at $100{ }^{\circ} \mathrm{C}$ for $30 \mathrm{~min}$. The $\mathrm{pH}$ of phosphorus containing solution was adjusted at $\mathrm{pH}=10$ with $\mathrm{NH}_{3}$ and then stirred for $2 \mathrm{~h}$. The 
phosphorus containing solution was added drop-by-drop to $\mathrm{Ca}+\mathrm{Ag}$ solution and stirred again for $2 \mathrm{~h}$, and after the chemical reaction, the deposited mixture was washed in deionized water (DIW) and dried at $100{ }^{\circ} \mathrm{C}$ for $72 \mathrm{~h}$. For the preparation of the Ag:Hap + D3 powders, a certain quantity of Ag:HAp was completely mixed with D3 powder from commercial tablets, namely $5.24 \mathrm{~g}$ Ag:HAp with 16 tablets of commercially available D3 vitamin $\left(\mathrm{C}_{27} \mathrm{H}_{44} \mathrm{O}\right)$ where the $\mathrm{D} 3$ concentration was: $\mathrm{x}(\mathrm{D} 3)=0.0057 \%, \mathrm{~m}(\mathrm{D} 3)=0.342 \mu \mathrm{g}$ (on a thin film of $200 \mathrm{~nm}$ thickness).

The Ag:HAp thin films were deposited on titanium substrates prepared before deposition by cleaning in organic solvents by a particular chemical procedure cleaning (the Ti disks were rinse with acetone several times and then left to dry at room temperature). The deposition of Ag:HAp thin films (from Ag:HAp nano-powders) of approximately $200 \mathrm{~nm}$ thickness was achieved by vacuum deposition at a medium pressure of $p \sim 6.5 \times 10^{-5}$ torr from a tungsten (W) boat, at a maximum current intensity: $\mathrm{I}=150 \mathrm{~A}$, evaporation time $\mathrm{t} \sim 150 \mathrm{~s}$ The thin film color was generally dark green and showed a good adherence. The UV controlled irradiation had the following characteristics: $\lambda=365 \mathrm{~nm}$, $\mathrm{P}_{\text {optical integral }}=30 \mathrm{~W}$, optical power density $\mathrm{D}_{\mathrm{P}}=0.066 \mathrm{~mW} / \mathrm{cm}^{2}$.

\subsection{Characterization Methods}

The chemical composition of irradiated and unirradiated Ag:HAp coatings was investigated by X-ray photoelectron spectroscopy (XPS) technique. A Multimethod SPECS surface analysis system (using an $\mathrm{Al} \mathrm{K} \alpha$ monochromatic radiation) was used for this purpose. The pressure in the analysis chamber was set at $\sim 3 \times 10^{-9}$ torr. The XPS spectra was recorded using 400 recording channels with an energy window $\mathrm{w}=20 \mathrm{eV}$ and a Pass Energy of $20 \mathrm{eV}$. The line of $\mathrm{C} 1 \mathrm{~s}$ from $284.8 \mathrm{eV}$ was used as reference. All the recorded XPS spectra were analyzed using Spectral Data Processor v. 2.3 (SDP) software.

Atomic force microscopy (AFM) was used to study the surface morphology of the coatings. An NT-MDT NTEGRA Probe Nano Laboratory instrument (NT-MDT, Moscow, Russia) operated in non-contact mode was used to obtain the surface topographies of the coatings. Moreover, a silicon NT-MDT NSG01 cantilever coated with a $35 \mathrm{~nm}$ gold layer was used during the measurements. The AFM topographies were obtained on a surface area of $5 \times 5 \mu \mathrm{m}^{2}$ and the root means square (RMS) was determined to evaluate for the surface roughness.

Using a Hitachi S4500 (Hitachi, Tokyo, Japan) scanning electron microscope equipped with an energy dispersive $x$-ray (EDX) detection system the surface morphology and chemical composition of the samples were investigated. The SEM images were acquired in SE mode.

Spectroscopic information regarding the samples was obtained by Fourier transform infrared spectroscopy-attenuated total reflection (FTIR-ATR) spectroscopy (Perkin Elmer SP-100, Waltham, MA, USA). Therefore, the spectra were recorded in the range $500-4000 \mathrm{~cm}^{-1}$ using a Perkin Elmer SP-100 spectrometer (Waltham, MA, USA). The resolution of the FTIR-ATR spectra was $4 \mathrm{~cm}^{-1}$.

A Leica confocal scanning laser microscope (CSLM) TCS-SP (Wetzlar, Germany), equipped with a $40 \times$ HCX PL APO NA 0.75 dry objective (Leica Microsystems CMS, Germany), and an Ar ion laser with a laser line at $488 \mathrm{~nm}$ was used in both fluorescence and reflection modes.

\subsection{Antifungal Activity Evaluation}

The antifungal activity of the non-irradiated and irradiated Ag:HAp/Ti and Ag:Hap + D3/Ti thin films, for various time intervals was assessed using a Candida albicans ATCC 10,231 reference fungal strain (ATCC, Old Town Manassas, VA, USA). The antifungal properties were determined with the aid of fungal suspensions of a known fungal density $\left(\sim 1.5 \times 10^{6}\right.$ colony forming units $\left.(\mathrm{CFU}) / \mathrm{mL}\right)$, obtained from 15 to $18 \mathrm{~h}$ fungal cultures. The samples were incubated at $37^{\circ} \mathrm{C}$ for $72 \mathrm{~h}$ with the fungal suspensions in order to evaluate the temporal dynamics of the fungal cells' development, after 24,48 , and $72 \mathrm{~h}$. The experi- 
ments were performed in triplicate and the results were expressed as mean \pm standard deviation (SD). CLSM imaging was performed to assess the fungal biofilm development on the surface of non-irradiated and irradiated Ag:HAp/Ti and Ag:HAp+D3/Ti thin film, after $24 \mathrm{~h}$ of incubation, by visualization of the adherent fungal cells on the substrates. For the CLSM investigations, the thin films incubated for $24 \mathrm{~h}$ with C. albicans fungal culture were washed using sterile saline buffer solution (PBS), in order to remove the unattached fungal cells. The fungal cells were fixed with cold methanol and stained in the dark using propidium iodide (PI) at room temperature. The samples were visualized immediately after staining and the images were recorded both in reflection and fluorescence modes using CSLM.

\subsection{Biocompatibility Assays}

The cytotoxicity of the thin films was investigated using a HeLa cell line. The in vitro assays regarding the influence of non-irradiated and irradiated Ag:HAp/Ti and Ag:Hap + D3/Ti thin films on the adherence of human cells were conducted after $24 \mathrm{~h}$ of incubation. For the cytotoxicity assays, the HeLa cells were grown in Dulbecco's modified Eagle's medium at $37{ }^{\circ} \mathrm{C}, 5 \% \mathrm{CO}_{2}$ and humid atmosphere. After incubation, the cells were fixed in 70\% ethanol, stained with PI and visualized using a Zeiss Observer D1 microscope $(\lambda=546 \mathrm{~nm})$. A duplicate of each sample was subjected to Trypan blue cell counting. Additional cytotoxicity studies of the Ag:HAp/Ti and Ag:Hap + D3/Ti thin films before and after UV irradiation were performed using human fetal osteoblasts (hFOB 1.19) from the American Type Culture Collection (ATCC). For this purpose, the cells were grown in Dulbecco's modified Eagle's medium (DMEM) and incubated at with $5 \% \mathrm{CO}_{2}$ at $37^{\circ} \mathrm{C}$. The obtained cultures were incubated for $24 \mathrm{~h}$ with the samples at $37^{\circ} \mathrm{C}$ in an atmosphere with $5 \% \mathrm{CO}_{2}$. After $24 \mathrm{~h}$ of incubation with the samples the cells were visualized under an inverted microscope. Furthermore, the cell viability of the hFOB 1.19 cells incubated with Ag:HAp/Ti and Ag:HAp+D3/Ti thin films before and after UV irradiation was assessed by MTT (3-4,5-dimethylthiazol 2,5-diphenyltetrazolium bromide) assay, in agreement with previous studies [6]. The experiments were performed 3 times and the results were presented as mean $\pm \mathrm{SD}$.

\section{Results}

X-ray Photoelectron Spectroscopy analysis was used to investigate the principal lines of constituent elements ( $\mathrm{Ca}, \mathrm{P}, \mathrm{Ag}, \mathrm{O}, \mathrm{C})$ of Ag:HAp/Ti sample before and after UV irradiation with a quantitative analysis of concentration ratio. The XPS spectra of Ca2p, P2p and Ag3d lines measured from the Ag:HAp/Ti thin films in the initial stage of the sample are as follows, with the observation that the calculated value of the modified Auger parameter using Ag3d and Ag M4N45N45 is $726.4 \mathrm{eV}$, which clearly indicates the presence of a metallic state. The XPS general spectrum of the Ag:HAp/Ti coating in the initial stage and the high spectra of constituent elements are presented in Figure 1a-f. For light elements, namely oxygen (Figure 1e) and carbon (Figure 1f) the XPS analysis is more extended due to the presence of different chemical bonds. The O1s signal and C1s signal are present in the initial HAp:Ag/Ti films and can be observed in Figure 1e,f, i.e., for O1s (peak at binding energy (BE) of $531.13 \mathrm{eV}$ was assigned to $\mathrm{O}$ in HAp; peak at binding energy (BE) of $532.18 \mathrm{eV}$ was associated to $\mathrm{C}$ bonds while the peak at $\mathrm{BE}$ of $533.30 \mathrm{eV}$ was assigned to $\mathrm{OH}$ and $\mathrm{H}_{2} \mathrm{O}$ traces); for $\mathrm{C} 1 \mathrm{~s}$ (peak at $\mathrm{BE}$ of $284.80 \mathrm{eV}$ was associated to $\mathrm{C}-\mathrm{C}$ and $\mathrm{C}-\mathrm{H}$ bonds used as reference lines for other spectra; peak at $\mathrm{BE}$ of $286.54 \mathrm{eV}$ was assigned to simple $\mathrm{O}$ bond; the peak at $\mathrm{BE}$ of $289.02 \mathrm{eV}$ was associated to triple $\mathrm{O}$ bonds, or COOR type compounds). 

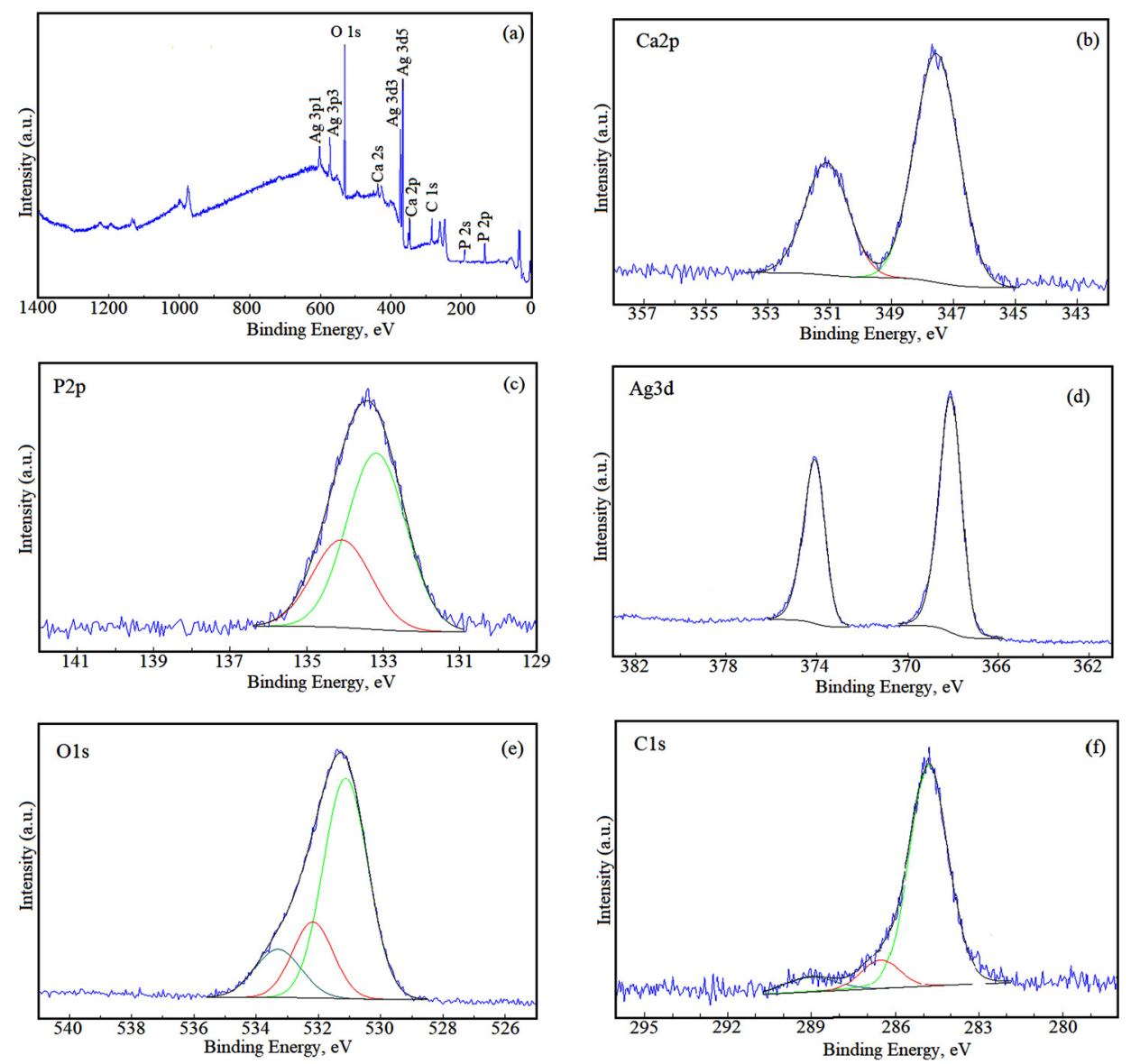

Figure 1. XPS survey (a), Ca2p (b), P2p(c), Ag3d (d), O1s (e) and C1s (f) of Ag:HAp/Ti thin film (as deposited) before UV irradiation.

The Ag:HAp + D3 coatings were also studied before and after UV irradiation at $140 \mathrm{~min}, 410 \mathrm{~min}$ and $760 \mathrm{~min}$. The general XPS scan spectra of the Ag:HAp + D3 coating before UV irradiation and XPS narrow scan spectra of Ca2p, P2p, O1s, Ag3d and C1s are presented in Figure 2. In the case of Ca2p and P2p deconvolution there are no differences between the Ag:HAp and Ag:HAp + D3 coatings before irradiation. The XPS spectral peaks for Ca2p1/3 were composed into one component at around $351.09 \mathrm{eV}$ while the peaks for Ca2p3/2 was located at around $347.55 \mathrm{eV}$. In agreement with previous studies [20], the peak located at around $347.55 \mathrm{eV}$ could show that calcium atoms were bound to a $\mathrm{PO}_{3}^{4}$ (phosphate group). The high-resolution P 2p region of Ag:HAp and Ag:HAp + D3 coatings was deconvoluted into two components at BEs around 133.18 and $134.08 \mathrm{eV}$, values that are appropriate to the binding energies specific to hydroxyapatite [21,22]. The high resolution XPS spectra of the Ag 3d region of Ag:HAp and Ag:HAp + D3 coatings before irradiation is revealed by Figure $1 \mathrm{~d}$ and Figure $4 \mathrm{f}$. The Ag3d spectrum exhibits a doublet with an $\mathrm{Ag} 3 \mathrm{~d} 5 / 2$ and $\mathrm{Ag} 3 \mathrm{~d} 3 / 2$ component located at BEs of 368.08 and $374.09 \mathrm{eV}$ assigned to silver ions in $\mathrm{Ag}^{2+}$ and $\mathrm{Ag}-\mathrm{O}$, in accordance with values from former literature [23-25].

A slight difference in the $\mathrm{O} 1 \mathrm{~s}$ and $\mathrm{C} 1 \mathrm{~s}$ deconvolution of Ag:HAp + 3D sample (Figure 2d) compared to Ag:HAp sample (Figure 1e) was observed. The high-resolution O1s region of sample Ag:HAp was deconvoluted into three peaks at BEs of 531.18, 532.20 and $533.20 \mathrm{eV}$ while the high resolution O1s region of sample Ag:HAp + D was deconvoluted into two peaks at BEs of 531.20 and $532.36 \mathrm{eV}$. The binding energy at around 531.2 and $533.2 \mathrm{eV}$ were assigned to the $\mathrm{O}$ in hydroxyapatite and $-\mathrm{OH}$ groups, respectively [20]. The peak at $\mathrm{BE}$ of $532.2 \mathrm{eV}$ could correspond to simple $\mathrm{C}-\mathrm{O}$ bonds [21,22]. The high-resolution $\mathrm{C}$ 1s region of sample Ag:HAp was deconvoluted into three peaks while high resolution $\mathrm{C}$ 1s region of sample Ag:Hap + D3 was deconvoluted into four peaks. The peaks at BE 
of 284.80, 286.54, and $289.01 \mathrm{eV}$ were presented in the high-resolution C1s region of both samples (Ag:HAp and Ag:HAp + D3). The peak at BE of $288.07 \mathrm{eV}$ (Figure 3f) that appears in the high resolution $\mathrm{C} 1 \mathrm{~s}$ region of sample Ag:HAp + D3 could be assigned to double bonds with $\mathrm{O}$ e.g., $\mathrm{C}=\mathrm{O}$ or $\mathrm{O}-\mathrm{C}-\mathrm{O}$, respectively [23].
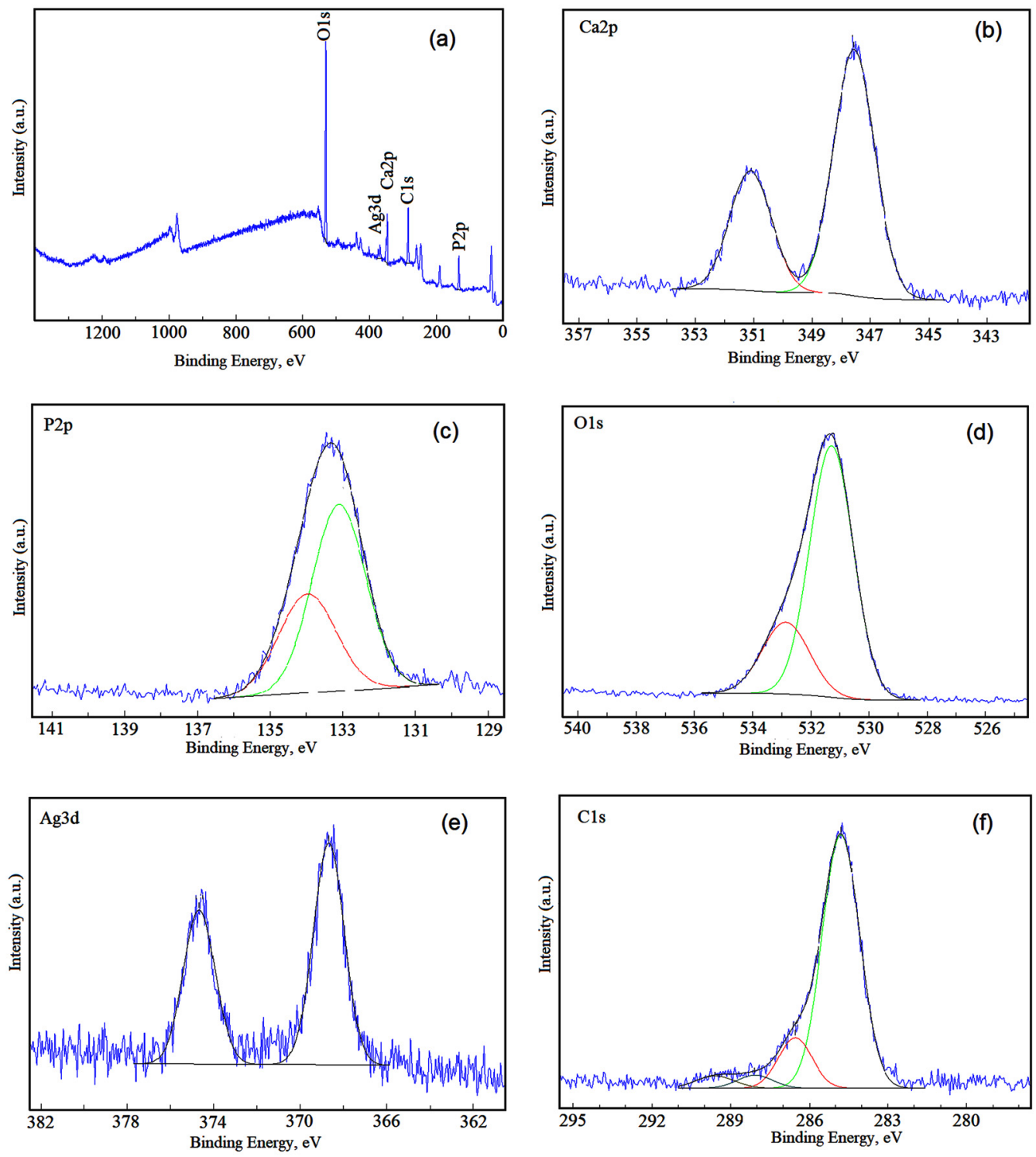

Figure 2. XPS survey (a), Ca2p (b), P2p(c), O1s (d), Ag3d (e) and C1s (f), of Ag:Hap + D3 coatings before UV irradiation.

It is worth to mention that during UV irradiance no notable difference in the general aspect of XPS spectra (Figures 3-6) has occurred, as suggested by the general aspect of the line observed The evolution of Ca2p, Ag3d, P2p, O1s signal arisen from Ag:HAp/Ti coating during UV irradiance at 140, 230, 410, and 760 min were presented in Figure 3a-d. The evolution of $\mathrm{C}$ 1s signal arisen from HAp:Ag/Ti coating during UV irradiance was shown in Figure 3e (UV irradiance at 140, 230, and $410 \mathrm{~min}$ ) and Figure $3 \mathrm{f}$ (UV irradiance at $760 \mathrm{~min}$ ).

A small difference in the general aspect of the base line can be observed in Figure $2 \mathrm{~d}$ for O1s signal, while for C1s signal a small difference in spectra was observed at deconvolution, that appeared after $t_{\text {irad }}=140 \mathrm{~min}$, a difference related to a signal arisen from a double $\mathrm{O}$ bond, as can be observed in Figure 3e. 
In Figure $3 \mathrm{f}$ it is presented the XPS spectrum of C1s signal arisen after a final UV irradiation of $\mathrm{t}=760 \mathrm{~min}$. In the $\mathrm{C} 1 \mathrm{~s}$ spectrum, the peak located at $\mathrm{BE}$ of $284.8 \mathrm{eV}$ was related to $\mathrm{C}-\mathrm{C}$ and $\mathrm{C}-\mathrm{H}$ bonds, the peak located at $\mathrm{BE}$ of $286.35 \mathrm{eV}$ was assigned to simple $\mathrm{O}$ bonds (C-O), while the peaks located at BEs of $287.96 \mathrm{eV}$ and $289.06 \mathrm{eV}$ were attributed to double bonds with $\mathrm{O}$ e.g., $\mathrm{C}=\mathrm{O}$ or $\mathrm{O}-\mathrm{C}-\mathrm{O}$, and triple $\mathrm{O}$ bonds. o As can be observed there is an increase in the intensity signal from simple $\mathrm{C}-\mathrm{O}$ bonds and also a slight increase in the intensity of double and triple Carbon-Oxygen bonds, these bonds are more intense in the structure of Ag:HAp/Ti thin film after irradiation.
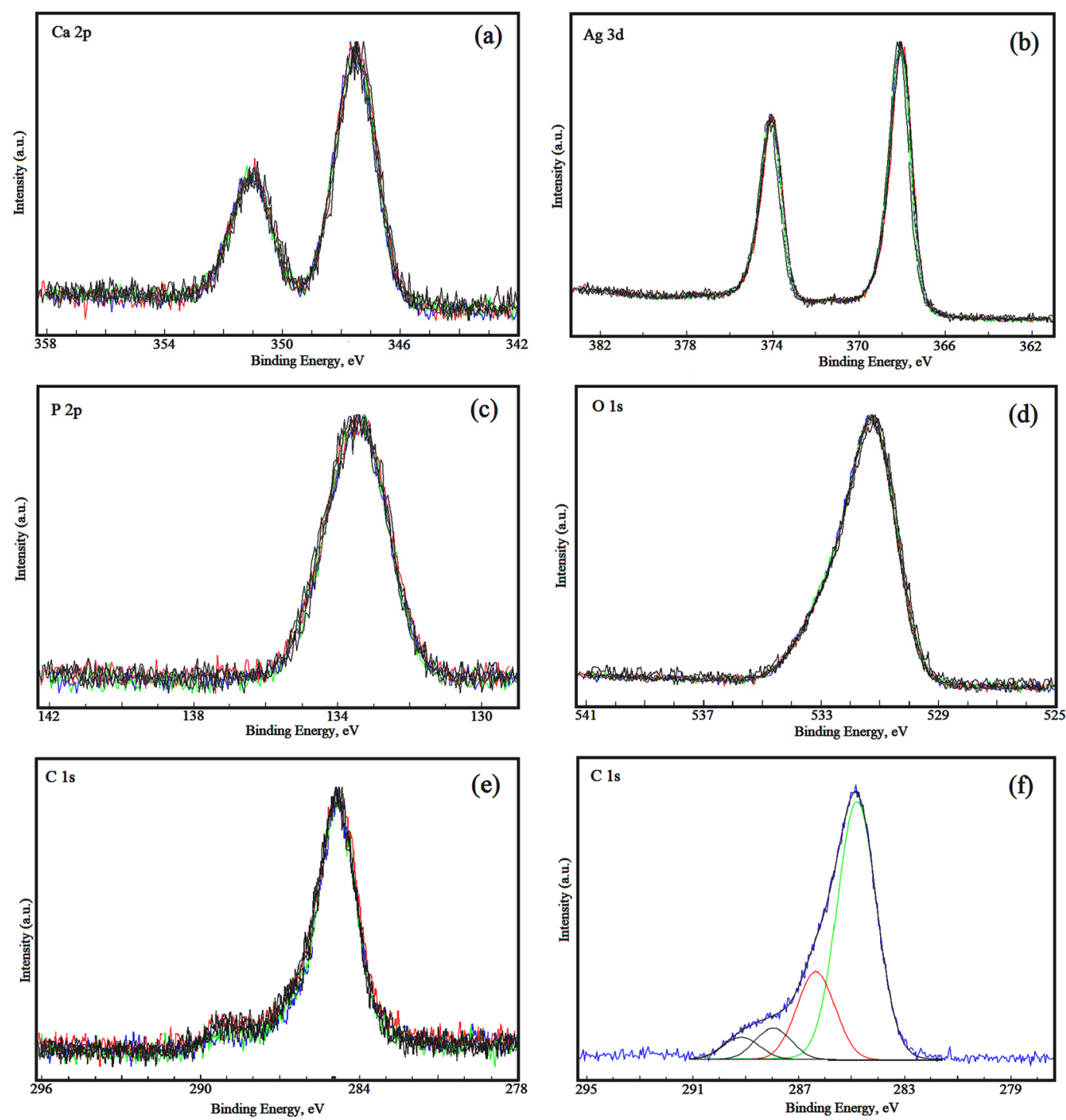

Figure 3. Evolution of Ca2p (a), Ag3d (b), P2p (c), O1s (d) signal arisen from Ag:HAp/Ti thin film during UV irradiance at $140 \mathrm{~min}, 230 \mathrm{~min}, 410 \mathrm{~min}$, and $760 \mathrm{~min}$. Evolution of C1s signal arisen from HAp:Ag/Ti thin film during UV irradiance at $140 \mathrm{~min}, 230 \mathrm{~min}, 410 \mathrm{~min}(\mathbf{e})$ and $760 \mathrm{~min}(\mathbf{f})$.

Figures 4-6 show the general XPS scan spectra and XPS narrow scan spectra of the constituent elements of the Ag: HAp + D3 coating after UV irradiation at $140 \mathrm{~min}, 410 \mathrm{~min}$ and $760 \mathrm{~min}$. As it can be seen in Figures 4-6, after UV irradiation of the Ag: HAp + D3 sample at 140, 410 and $760 \mathrm{~min}$ no changes were observed. The appearance of the general spectrum, as well as the XPS spectra of the constituent elements (C1s, O1s, Ca2p, P2p, and Ag3d) did not show significant changes following UV irradiation.

Unlike the Ag: HAp coating, in the case of Ag: HAp + D3 coating after UV irradiation, the high resolution XPS spectrum of P2p after deconvolution showed two components 
at BEs around 133.10 and $133.96 \mathrm{eV}$. The high resolution XPS spectrum of O1s (for Ag: HAp + D3 coating after UV irradiation) was deconvolved into two components at BEs around 531.28 and $532.86 \mathrm{eV}$ that could be assigned to the $\mathrm{O}$ in hydroxyapatite [26] and simple $\mathrm{C}-\mathrm{O}$ bonds $[27,28]$. The high-resolution XPS spectrum of $\mathrm{C} 1 \mathrm{~s}$ was deconvolved into four components and showed no significant changes after irradiation (even at $760 \mathrm{~min}$ UV irradiation). The four maxima resulting from the deconvolution were located at BEs around 284.80, 286.54, 288.07, and $289.59 \mathrm{eV}$ in agreement with previous studies [29].
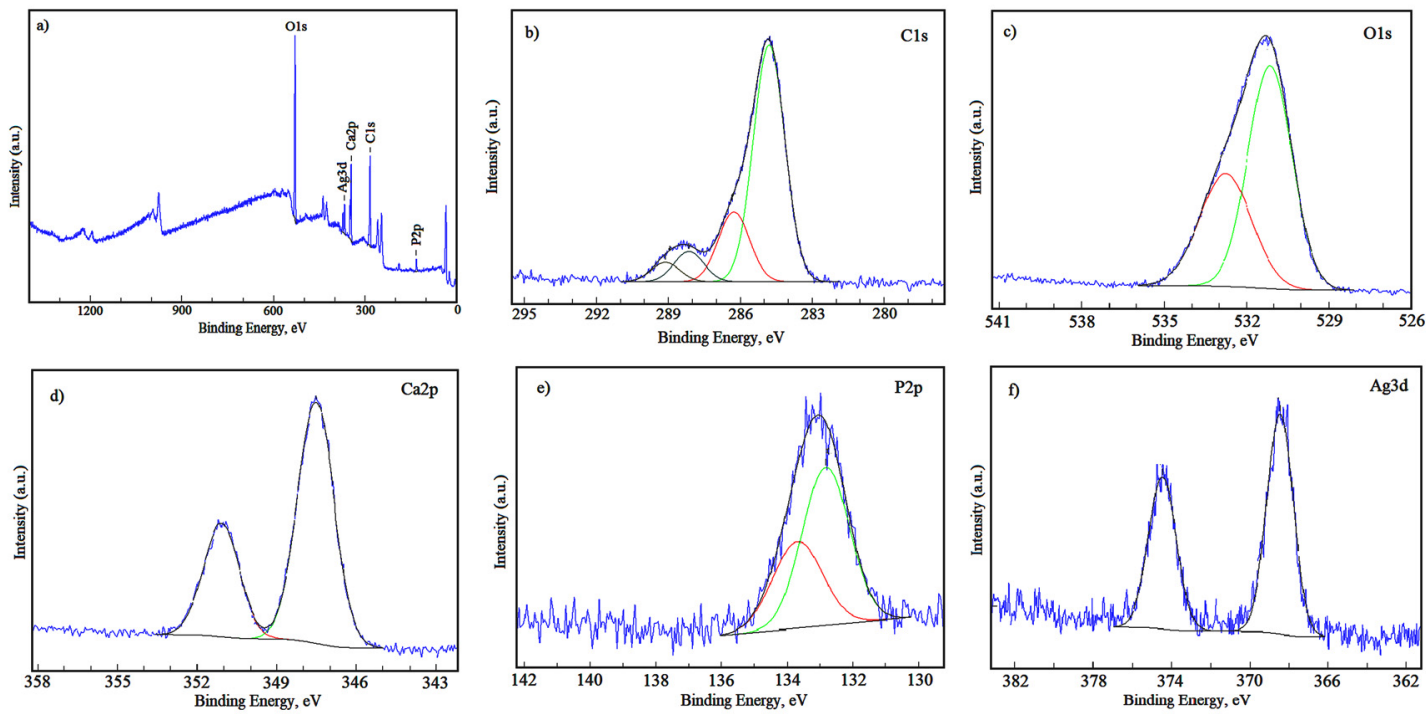

Figure 4. X-ray photoelectron spectroscopy (XPS) survey (a) and XPS narrow scan spectra of C1s (b), O1s (c), Ca2p (d), P2p (e), and Ag3d (f) of Ag:Hap + D3 coating after UV irradiation at $140 \mathrm{~min}$.
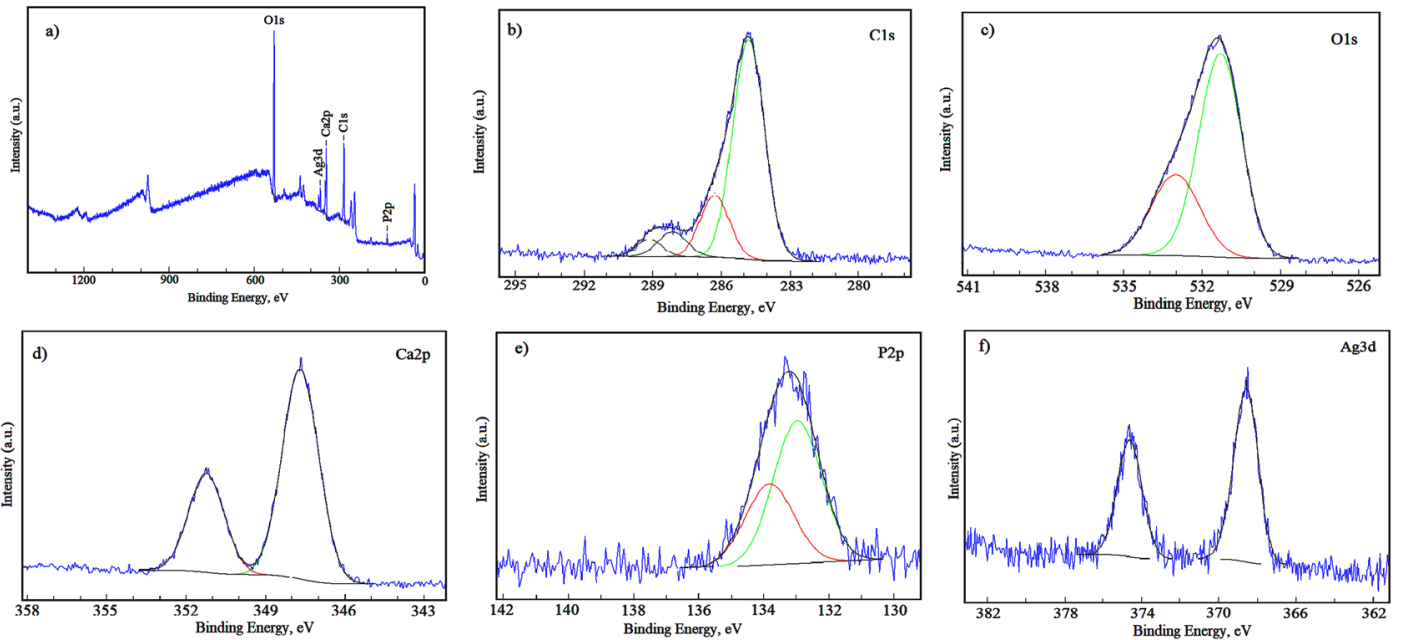

Figure 5. XPS survey (a) and XPS narrow scan spectra of C1s (b), O1s (c), Ca2p (d), P2p (e), and Ag3d (f) of Ag:Hap + D3 coating after UV irradiation at $410 \mathrm{~min}$. 

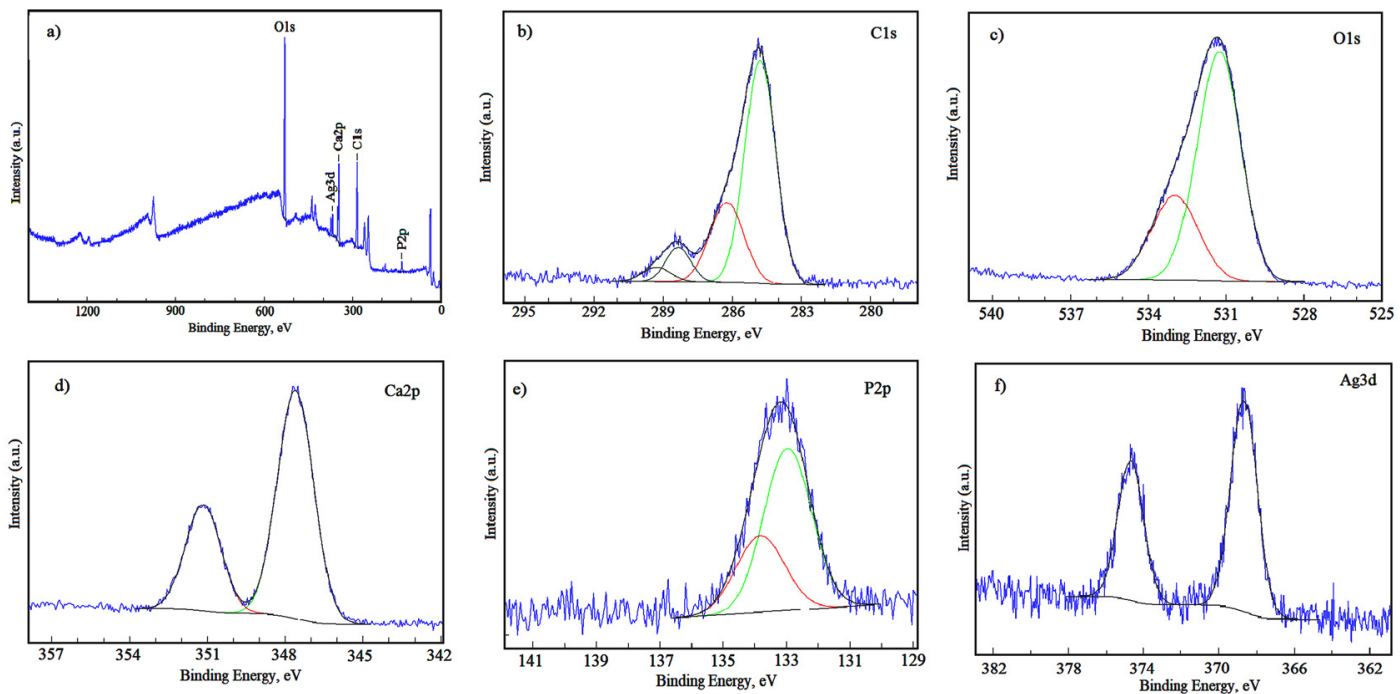

Figure 6. XPS survey (a) and XPS narrow scan spectra of C1s (b), O1s (c), Ca2p (d), P2p (e) and Ag3d (f) of Ag:Hap + D3 coating after UV irradiation at $760 \mathrm{~min}$.

Our results revealed that the oxygen content increases with the UV irradiation time for both studied coatings. The evolution of molar concentration ratio of oxygen on the unirradiated and irradiated Ag:HAp and Ag:Hap + D3 coatings are presented in Figure 7. Our results regarding the evolution of molar concentration ratio of oxygen on the UV irradiated Ag:HAp and Ag:Hap + D3 coatings are in good agreement with the anterior studies [30-34]. In previous studies regarding the surface changes and radical formation on hydroxyapatite by UV irradiation for inducing photocatalytic activation [30] it has been shown that an important role in increasing the oxygen content after irradiation is played by the presence of a thin layer of titanium oxide on the surface of titanium. Moreover, recent data presented in the literature $[35,36]$ highlighted that the thickness of titanium oxide layer depends on the fluidizing temperature (of the raw titanium powders) used for the obtaining of the Ti substrate.



Figure 7. Evolution of molar concentration ratio of oxygen on the unirradiated and irradiated Ag:HAp and Ag:Hap + D3 coatings.

Even if the main changes in the position of the XPS line are related to the carbon bonds, the XPS technique allowed us to evaluate the influence of UV irradiation on the coatings. In the XPS analysis, it was possible to highlight even the small differences of the $C$ signal at these levels of UV irradiation. 
The general aspect of Ag:HAp/Ti thin films were highlighted by different AFM images, and the characteristics of film roughness was measured by the RMS factor. The initial aspect of the surface is presented in Figure 8a and as can be observed there exist a conglomerate of small spheres with a random distribution, with an RMS factor of $243.2 \mathrm{~nm}$. The AFM image (Figure $8 \mathrm{~b}$ ) after an UV irradiance of $t=140$ min indicates a distribution with a highly disoriented aspect and with an increase tendency of roughness (RMS: $272.3 \mathrm{~nm}$ ). The AFM image (Figure 8c) after an UV irradiance of $t=230 \mathrm{~min}$ indicates a highly increased level of conglomerate distribution with a modified aspect sphere base element, expressed by an accentuated measured roughness (RMS: $525.8 \mathrm{~nm}$ ).


Figure 8. (a) Ag:HAp thin film on Ti substrate (initial aspect) RMS: $243.2 \mathrm{~nm}$; (b) Ag:HAp on Ti substrate thin film after UV irradiance of $\mathrm{t}=140 \mathrm{~min}$ (RMS:272.3 nm); (c) Ag:HAp thin film on Ti substrate after UV irradiance of $\mathrm{t}=230 \mathrm{~min}$ (RMS: $525.8 \mathrm{~nm}$ ); (d) Ag:HAp thin film on Ti substrate after UV irradiance of $\mathrm{t}=410 \mathrm{~min}$ (RMS: $241.3 \mathrm{~nm}$ ); (e) Ag:HAp thin film on Ti substrate after UV irradiance of $t=760 \mathrm{~min}$ (RMS: 185.8).

The AFM image (Figure 8d) after an UV irradiance of $t=410$ min indicates the presence of sphere conglomerates more gathered, with a general aspect as in the initial stage of the Ag:HAp sample, a situation illustrated by the value of measured roughness (RMS: $241.3 \mathrm{~nm}$ ). As a general remark, the AFM measurements are sensitive to UV irradiation effects and put into evidence the modifications of roughness characteristics. It is important to mention the presence of an effect of partly recovery of the mechanical surface characteristics in a moment of UV irradiance (i.e., aspect of Figure $8 \mathrm{~d}$ ), that can be viewed as an adaptation of the thin film of Ag:HAp/Ti to UV irradiation, probably as a prelude of a rapid degradation effect, a general effect present in various devices (e.g., rapid degradation in laser diodes [37]), a process known in biology as the momentary recovery of a patient before his death. It is worth to mention that the AFM measurements were located on the same area of the same irradiated sample at different irradiation levels. The sample was irradiated forward in order to put into evidence the effect upon Ag:HAp/Ti thin film, and it was remarked that after a cumulative time of $t=660 \mathrm{~min}$ the surface roughness suffered a decrease to RMS $=198 \mathrm{~nm}$. The final irradiation at a cumulative time of $t=760 \mathrm{~min}$ showed an effect of surface polishing with a decrease of RMS $=185.8$, in a general tendency of ordering the surface aspect with a smoother characteristic, as can be observed in Figure 8e. It is worth to mention that the expected effect of rapid degradation was not evidenced at this gradual and cumulative UVA irradiation level.

Figure 9 shows the initial appearance of the Ag:Hap + D3 thin film surface on Ti substrate before (Figure 9a) and after irradiation (Figure 9b). The general appearance of 
the Ag:HAp + D3 thin film prior to UV irradiation showed nano-spheres that are evenly distributed on the surface, with an RMS factor equal with $188.7 \mathrm{~nm}$ (Figure 9a). After UV irradiation of the surface of Ag:HAp + D3 thin film on Ti substrate, RMS was equal to $163.5 \mathrm{~nm}$ (Figure 9b). As in the case of Ag:HAp samples, in the case of Ag:Hap + D3 samples, a smoothing effect of the surface and a decrease of RMS were observed as a result of UV irradiation of the surface. As a result, we could say that the samples containing D3 present a smoother and more orderly surface as a result of UV irradiation.
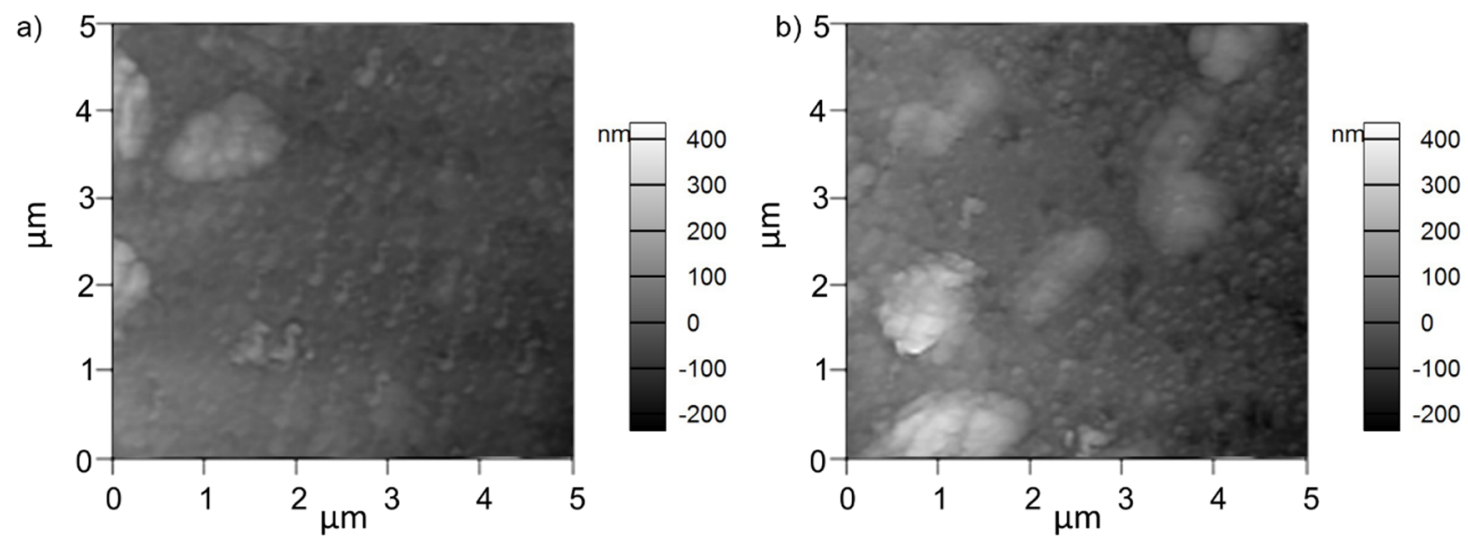

Figure 9. (a) Ag:Hap + D3 thin film on Ti substrate before UV irradiation; (b) Ag:HAp+D3 thin film on UV irradiance after UV irradiation of $t=230 \mathrm{~min}$.

The evolution of surface roughness as it was presented from AFM measurements has evidenced a process of increasing the surface order after UV irradiation that was consistent also in the XPS signals of the other elements $(\mathrm{C}, \mathrm{O}, \mathrm{P})$.

The IR characteristics of initial sample of Ag:HAp/Ti are presented in Figure 10a where the spectral characteristics indicates the presence of various vibrational modes corresponding to phosphates and hydroxyl groups. Phosphate $\mathrm{PO}_{4}{ }^{3-}$ groups in the apatite environment correspond to $563,603,634,960$, and $1000 \div 1100) \mathrm{cm}^{-1}$ and the hydroxyl group - $\mathrm{OH}$ the peaks noticed at 631 and $3569 \mathrm{~cm}^{-1}$ [38-41]. The broad bands (1600$1700) \mathrm{cm}^{-1}$ and (3200-3600) $\mathrm{cm}^{-1}$ correspond to $\mathrm{H}-\mathrm{O}-\mathrm{H}$ bands of lattice water with a band at $3445 \mathrm{~cm}^{-1}$ related to the presence of organized water in the structure of HAp. As it was stated [38] these large bands attributed to adsorbed water are diminished in Ag:HAp/Ti as compared to HAp where the changes are related probably to the substitution of $\mathrm{Ag}^{+}$ from $\mathrm{Ca}^{2+}$ into the lattice of HAp. The mark of Ag signal in Ag:HAp/Ti signals can be observed also in the peak of hydrogen phosphate group $\mathrm{HPO}_{4}{ }^{2-}$ at $875 \mathrm{~cm}^{-1}$ and in the small band of $\mathrm{CO}^{2-}$ at $1384 \mathrm{~cm}^{-1}$ where in the spectrum was present the signal related to an atomic ratio $\mathrm{Ag} / \mathrm{Ca}+\mathrm{Ag}$ [9]. It was stated [42] that the vibration band at $876 \mathrm{~cm}^{-1}$ related to $\mathrm{CO}_{3}{ }^{2-}$ becomes sharper in $\mathrm{Ag}^{-}: \mathrm{HAp}$ spectrum and the corresponding bands of 1415 and $1482 \mathrm{~cm}^{-1}$ are shifted in Ag:HAp compared to HAp a fact that is viewed also that a mark of Ag doping. In the Ag:HAp/Ti spectrum there exists a large band $(1750-2600) \mathrm{cm}^{-1}$, also cited in the literature [42] especially in the region (2250-2500) $\mathrm{cm}^{-1}$ that probably is related to Ag signal. After an UV irradiance of $t=140$ min (Figure 10b) the signal intensity in the region (1350-1750) $\mathrm{cm}^{-1}$ is increased, as well as the increased signal intensity in (1750-2600) $\mathrm{cm}^{-1}$ band probably related to the presence of $\mathrm{Ag}$ in apatite. As it was observed from the XPS signal and AFM analysis, the roughness of the Ag:HAp thin film is increasing suggesting a possible migration of Ag from the surface, a process that corresponds to changes in the broad bands attributed to adsorbed water, partly to changes in Ag signal related to the migration of $\mathrm{Ag}$ from $\mathrm{Ca}^{2+}$ site in the lattice of HAp. After an UV irradiance of $t=230 \mathrm{~min}$ (Figure 10c) a more pronounced increase in intensity signal in (1750-2600) $\mathrm{cm}^{-1}$ band region and a pronounced modification of intensity in (3200-3600) $\mathrm{cm}^{-1}$ region were noticed. These UV modifications showed that the process continued with broad bands modifications (e.g., adsorbed water band) and these changes 
occurred under the influence of irradiation, activate the antifungal properties of samples. After an UV irradiance of $t=410 \mathrm{~min}$ (Figure 10d) an intense signal was recovered in the broad band of (1750-2600) $\mathrm{cm}^{-1}$ and (3200-3600) $\mathrm{cm}^{-1}$ region. The effect of final UV irradiance on Ag:HAp/Ti thin film after an irradiance time of $t=760 \mathrm{~min}$ can be observed Figure 10e. As it is noticed the IR spectra look completely different after UV irradiation. The phosphate and hydroxyl groups and bending band $\mathrm{O}-\mathrm{P}-\mathrm{O}$ have a sharper aspect under $1000 \mathrm{~cm}^{-1}$, the broad band of (1400-1750) $\mathrm{cm}^{-1}$ has a valley-top aspect and a less intense signal in the region (1750-2600) $\mathrm{cm}^{-1}$ assigned to a band probably related to Ag. However, the general aspect of the signal is the same. The Ag signal has shown slight modifications in (1400-1800) $\mathrm{cm}^{-1}$ band that is active during UV irradiation and finally at $\mathrm{t}=760 \mathrm{~min}$ it suffered an extinction, a mark as the initial major properties of Ag:HAp/Ti were irremediably affected by UV irradiation. The most pronounced modification is the signal decrease, closed to extinction in the region (3200-3600) $\mathrm{cm}^{-1}$ a band related to $\mathrm{H}-\mathrm{O}-\mathrm{H}$ bonds of lattice water. A possible conclusion is that in the irradiated thin film, Ag replaced water in the matrix of apatite, the new composition being suggested by the AFM and XPS measurements in the sensitive line of C1s. The degradation of Ag:HAp/Tithin films is complete in a process of rapid degradation under UV irradiation.
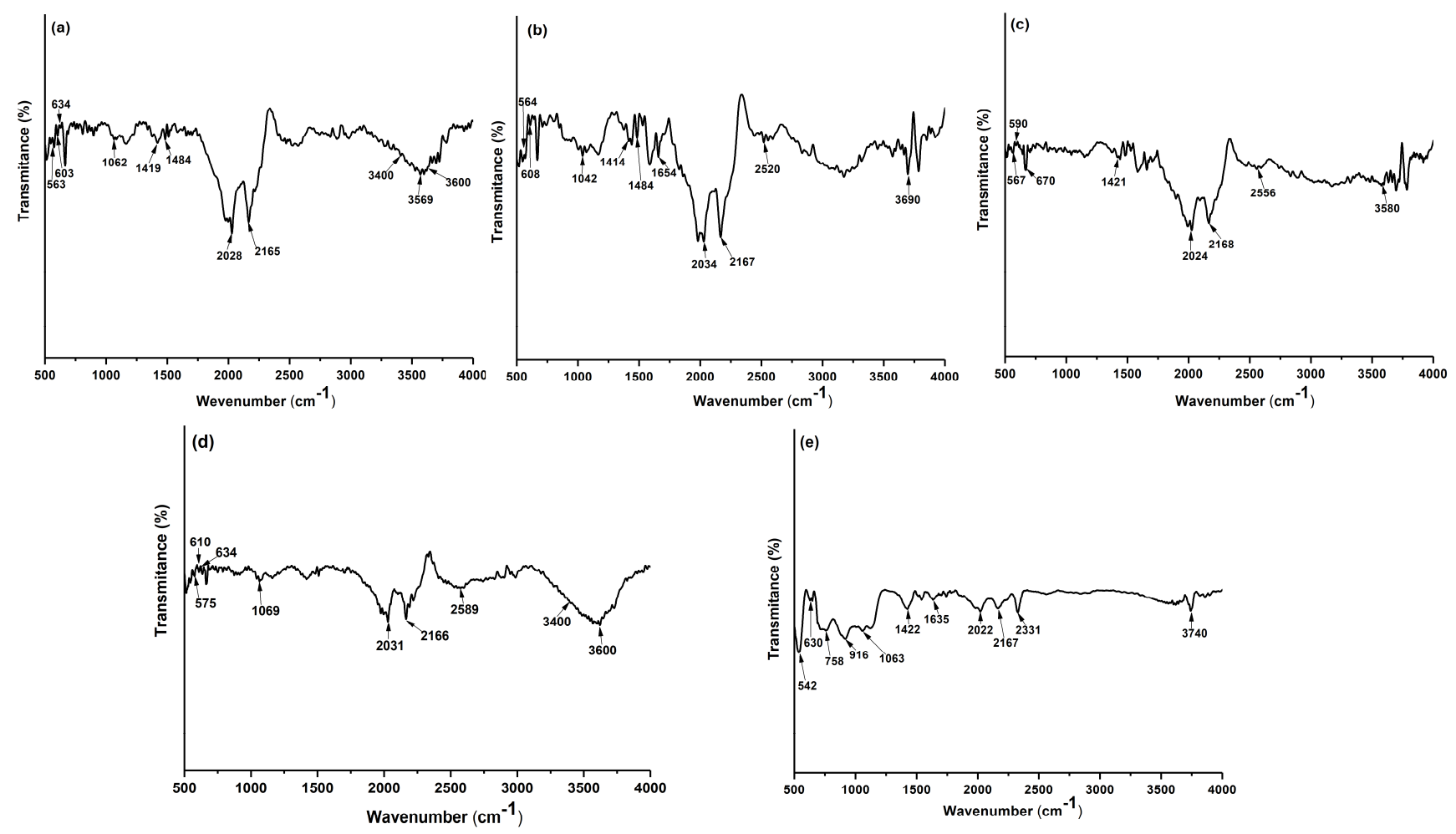

Figure 10. (a) Spectrum of Ag:HAp thin film on Ti substrate before UV irradiation; (b) spectrum of Ag:HAp thin film on Ti substrate after UV irradiation of $t=140 \mathrm{~min}$; (c)spectrum of Ag:HAp thin film on Ti substrate after UV irradiation of $\mathrm{t}=230$ min; (d) spectrum of Ag:HAp thin film on Ti substrate after UV irradiation of $\mathrm{t}=410 \mathrm{~min}$.; (e) spectrum of Ag:HAp thin film on Ti substrate after UV irradiation of $t=760 \mathrm{~min}$.

The FT-IR spectra of the Ag:HAp + D3 coating before (a) and after UV irradiation at 140 (b), 230 (c), and 760 min (d) were presented in Figure 11. Main specific bands of pure hydroxyapatite were identified for Ag:HAp + D coating before and after UV irradiation with some variations in absorption bands of $\mathrm{PO}_{4}{ }^{3-}$. The bands in the range of 562-564 cm $\mathrm{cm}^{-1}$ were assigned to O-P-O bending $\left(v_{4}\right)$. The presence of $\mathrm{PO}_{4}{ }^{3-}$ group was also noticed at $663 \mathrm{~cm}^{-1}$ and $636 \mathrm{~cm}^{-1}$. On the other hand, the bands in the range of $1000-2000 \mathrm{~cm}^{-1}$ indicating the presence of peaks assigned to $v(\mathrm{C}-\mathrm{O}-\mathrm{C})$ and $v(\mathrm{C}=\mathrm{O})$ at around $1149 \mathrm{~cm}^{-1}$ and $1630 \mathrm{~cm}^{-1}$ of Vitamin D3 [43]. Moreover, the peaks in the range 
of 1700-3000 $\mathrm{cm}^{-1}$ were assigned to $v\left(\mathrm{CH}_{2}\right)$ bands of Vitamin D3 [44]. The bands in the range of $3000-3600 \mathrm{~cm}^{-1}$ could be attributed to adsorbed water molecules and to the $\mathrm{O}-\mathrm{H}$ stretching. It is observed a decrease in signal intensity in (500-2600) $\mathrm{cm}^{-1}$ region. It should be noted that an increase in the intensity signal in (3200-3600) $\mathrm{cm}^{-1}$ region was observed when the time of UV irradiation increase.


Figure 11. (a) Spectrum of Ag:HAp + D3 thin film on Ti substrate before UV irradiation; (b) spectrum of Ag:HAp + D3 thin film on Ti substrate after UV irradiance of $t=140 \mathrm{~min}$; (c) spectrum of Ag:HAp + D3 thin film on Ti substrate after UV irradiance of $\mathrm{t}=230 \mathrm{~min}$; (d) spectrum of Ag:HAp + D3 thin film on Ti substrate after UV irradiance of $\mathrm{t}=760 \mathrm{~min}$.

The general view of Ag:HAp/Ti thin film is observed in the SEM image from Figure 12a. As it can be observed, the film presents a corrugated aspect, partly due to the deposition method, with a good adherence on the substrate (Ti). The morphology of the Ag:HAp/Ti thin film surface changes with increasing the UV irradiation time. A better structure of the Ag:HAp/Ti thin film surface was observed as the UV irradiation time increased from $140 \mathrm{~min}$ (Figure 12d) to $410 \mathrm{~min}$ (Figure 12h). Moreover, in the case of the irradiated sample for 760 min (Figure 12i), particles agglomerated at the nanometric scale can be observed on the Ag:HAp/Ti thin film surface. The EDS mapping of Ag:HAp/Ti thin film before UV irradiation presented in Figure $12 b, c, e, f$ showed that the constituent elements $(\mathrm{Ca}, \mathrm{P}, \mathrm{Ag}, \mathrm{O}$, and Ti) of the thin films are uniformly distributed.

Figure 13 showed the SEM microstructure information of the D3 in silver doped hydroxyapatite (Ag:HAp + D3) thin film on Ti substrate before (Figure 13a) and after UV irradiation (Figure 13b). The surface of the Ag:HAp + D3 thin film is multi-layered. The agglomerated nanometric particles were observed on the surface of the Ag:Hap + D3 thin film before and after UV irradiation. After UV irradiation for $230 \mathrm{~min}$ (Figure 13b) it is observed that the surface of the layer is better structured, the agglomerated nanometric 
particles being clearly observed. The behavior of the Ag:HAp + D3 sample after UV irradiation at $230 \mathrm{~min}$ is similar to that of the irradiated Ag:HAp sample for $760 \mathrm{~min}$.

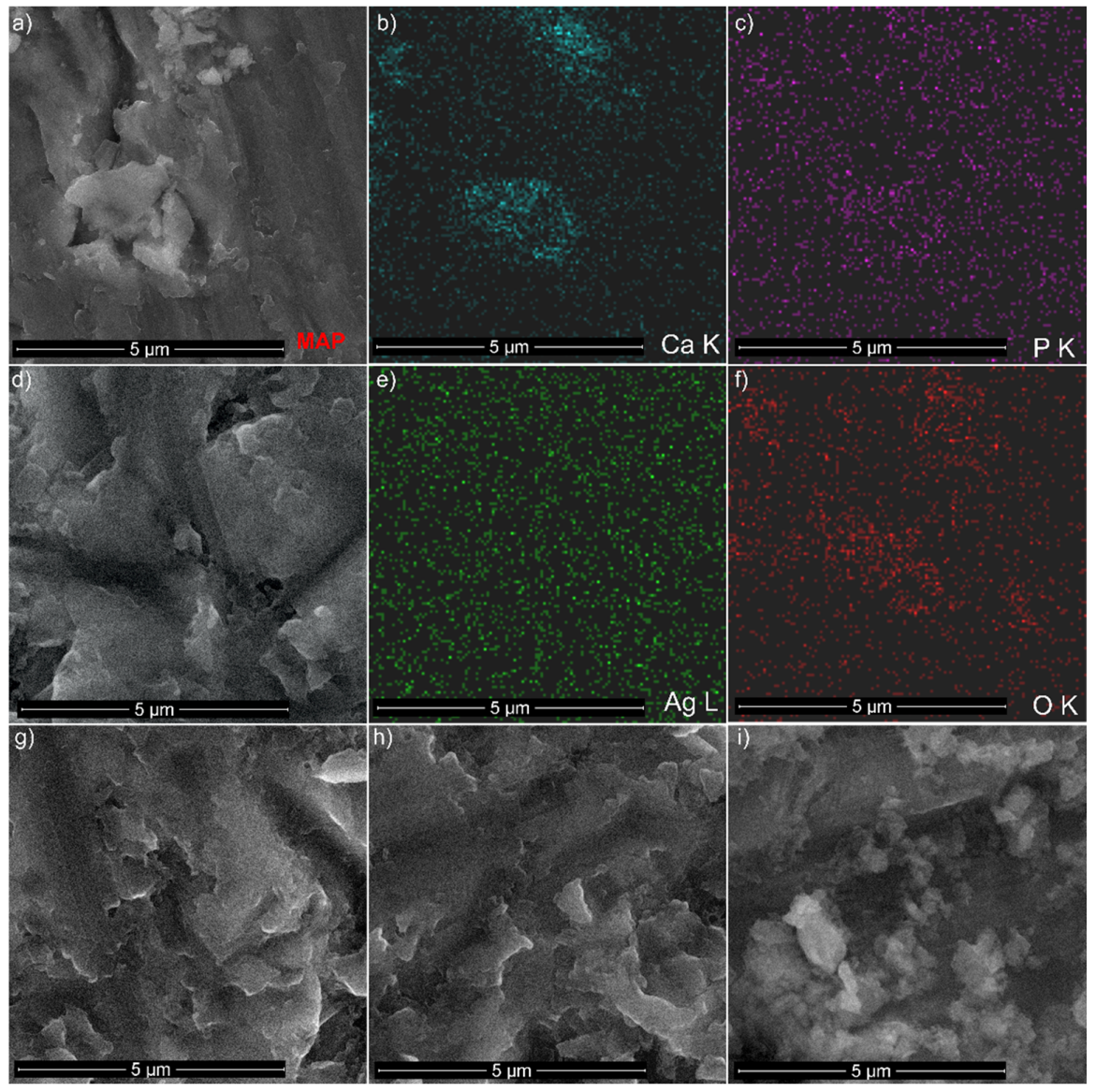

Figure 12. SEM images of Ag:HAp/Ti thin film before UV irradiation (a) and after UV irradiation for $140 \mathrm{~min}(\mathbf{d}), 230 \mathrm{~min}(\mathrm{~g}), 410 \mathrm{~min}(\mathbf{h})$, and $760 \mathrm{~min}(\mathbf{i})$. The EDS mapping spectrum of Ag:HAp/Ti thin film before UV irradiation $(\mathbf{b}, \mathbf{c}, \mathbf{e}, \mathbf{f})$.


Figure 13. SEM image of Ag:Hap + D3 thin film on Ti substrate before (a) and after UV irradiation (b).

As revealed by the results of XPS, FTIR, AFM, and SEM studies conducted on the unirradiated and UV irradiated Ag:HAp/Ti and Ag:Hap + D3/Ti coatings, the morphology, chemical composition and roughness of the surface are influenced by the time of exposure 
to UV radiation. Our results are in good agreement with the previous studies reported in the literature [31-34].

The effect of the UV irradiation on the antifungal effects of the Ag:HAp/Ti thin films and Ag:HAp + D3/Ti thin films was evaluated using a C. albicans ATCC 10,231 reference strain. C. albicans is known to be one of the most important opportunistic fungal strains, generally causing both hospital- and community-acquired infections, more frequently in immunosuppressed individuals [45]. In the last several years due to the emergence of multidrug resistant microorganisms, which is one of the major factors responsible for the increase of morbidity and mortality, the development of novel antimicrobial agents has been a focus of researchers worldwide [45,46]. In this context the present study focuses on the development of Ag:HAp/Ti and Ag:HAp + D3/Ti thin films and the assessment of the influence of UV irradiation on the antifungal properties of the Ag:HAp/Ti s and Ag:HAp + D3/Ti thin films. The temporal dynamics of the fungal cells development after being incubated with the non-irradiated and irradiated Ag:HAp/Ti thin and Ag:HAp+D3/Ti thin films was performed after 24,48 and $72 \mathrm{~h}$. The results of the antifungal assay are depicted in Figure 14.

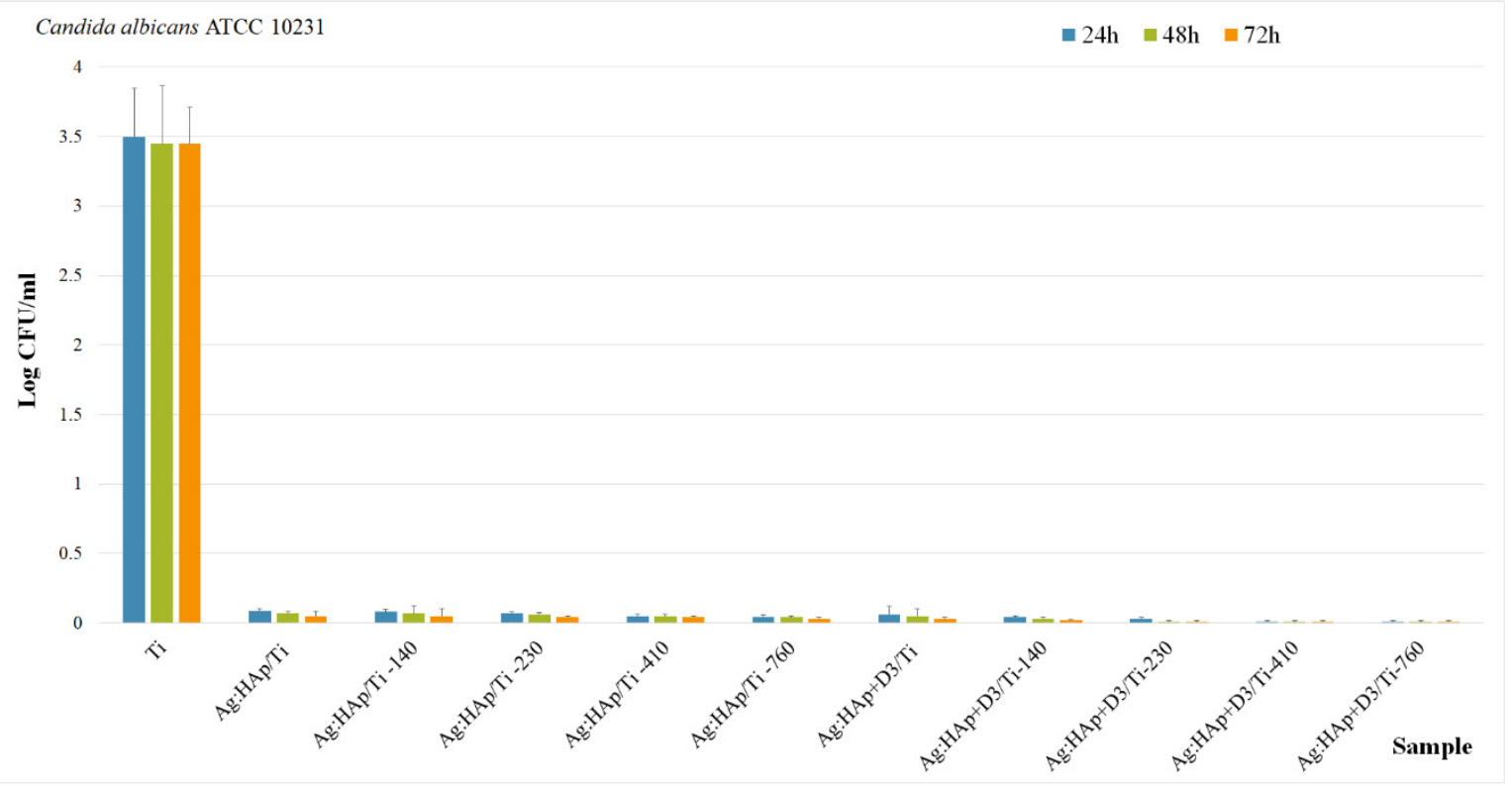

Figure 14. The effect of UV irradiated substrate against the development of Candida albicans ATCC 10,231 fungal cells.

The results of the antifungal studies are in agreement with previous reported studies regarding the antimicrobial activity of silver based composites and silver based composites thin films $[9,14,47-49]$ and emphasized that the antifungal effect of the Ag:HAp/Ti thin films is time dependent and it is also influenced by the UV radiation time. The antifungal assays demonstrated that all the investigated samples exhibited antifungal properties. The $\log \mathrm{CFU} / \mathrm{mL}$ values recorded for the fungal growth in the presence of the samples were lower than those obtained for the controls. The results suggested that an almost complete eradication of the C. albicans fungal cells was observed after $72 \mathrm{~h}$ of incubation for all the tested samples. Nonetheless the strongest antifungal activity after $24 \mathrm{~h}$ of incubation with the fungal suspension was exhibited in the case of Ag:HAp + D3/Ti-410 and Ag:HAp + D3/Ti-760 irradiated thin films. The results also suggested that the addition of D3 vitamin had a noticeable effect on the antifungal activity of the Ag:HAp/Ti thin films. The nonirradiated Ag:HAp/Ti inhibited the fungal development from a value of $0.09 \log \mathrm{CFU} / \mathrm{mL}$ at $24 \mathrm{~h}$ of incubation until a value of $0.05 \log \mathrm{CFU} / \mathrm{mL}$ after $72 \mathrm{~h}$ of incubation. Meanwhile the Ag:HAp + D3/Ti thin films managed to inhibit the C. albicans fungal development from a value of $0.06 \log \mathrm{CFU} / \mathrm{mL}$ after $24 \mathrm{~h}$ of incubation to $0.03 \mathrm{LogCFU} / \mathrm{mL}$ after $72 \mathrm{~h}$ of 
incubation. Moreover, the best inhibitory effect was observed in the case of the Ag:HAp + D3/Ti-760 irradiated thin film, thus emphasizing that the addition of D3 and also the UV irradiation have enhanced the antifungal activity of the thin films. This effect could be attributed to the fact that usually, the synthesis of vitamin $D$ in nature is strictly correlated with the presence of UV radiation [50,51]. The quantitative assay's results also suggested that for the Ag:HAp + D3/Ti-230 almost a complete eradication of the fungal cells after $72 \mathrm{~h}$ of incubation was achieved.

The development and adhesion of C. albicans cells on the surface of Ag:HAp/Ti and Ag:HAp + D3/Ti thin films after $24 \mathrm{~h}$ of incubation was also examined using the CLSM technique. The results of the CLSM investigations are depicted in Figure 15. The 2D CLSM images emphasized that all the samples considerably inhibited the development of C. albicans fungal cells compared to the Ti disc used as control. Moreover, CLSM images also revealed that the thin films did not allowed the fungal cells to proliferate and develop fungal biofilms.
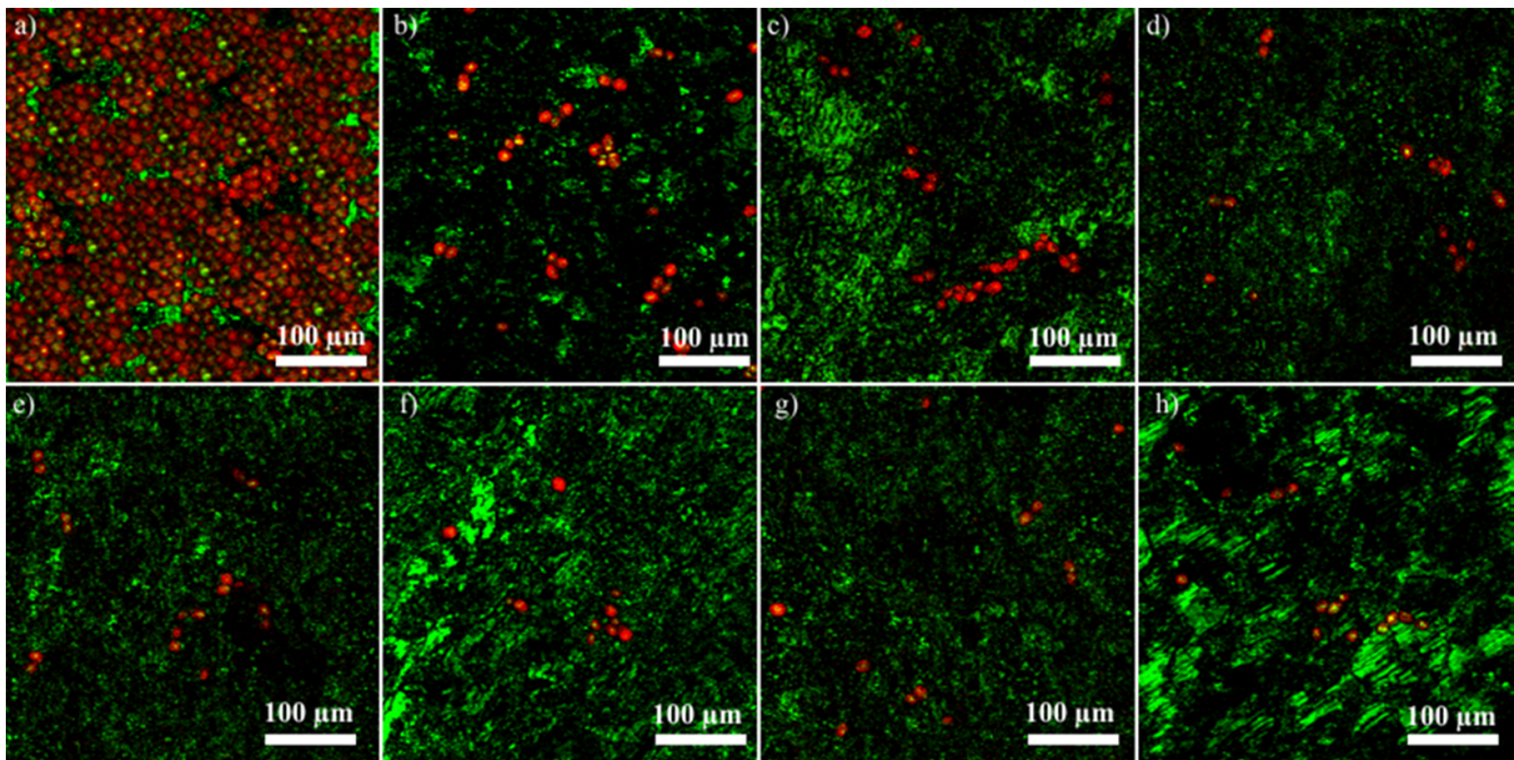

Figure 15. 2D confocal laser scanning microscopy (CLSM) images of Candida albicans ATCC 10,231 adhesion on Ti discs (fluorescence channel in red and reflection channel in green pseudocolours) (a), Ag:HAp/Ti (b), Ag:HAp/Ti-140 (c), Ag:HAp/Ti-230 (d), Ag:HAp/Ti-410 (e), Ag:HAp/Ti-760 (f), Ag:HAp + D3/Ti (g), Ag:HAp+D3/Ti-230 (h) after 24 h of incubation.

The visualization of the C. albicans fungal cells developed on the surface of Ag:HAp/Ti thin films and $\mathrm{Ag}: \mathrm{HAp}+\mathrm{D}_{3} /$ Ti before and after irradiation, evidenced that the surviving C. albicans cells were intact having round morphology and a smooth surface characteristic to $C$. albicans. Furthermore, the CLSM examination confirmed the results obtained by the qualitative antimicrobial assay and highlighted that the antimicrobial properties of the samples were influenced both by the irradiation time and the presence of vitamin D. More than that, the images showed that after $24 \mathrm{~h}$ of incubation the stronger antifungal activity was exhibited in the case of Ag:HAp/Ti-760 and Ag:HAp + D3/Ti-230 irradiated thin films. Furthermore, a 3D representation of the CLSM 2D images of the surviving C. albicans fungal cells that adhered on the surface of Ag:HAp/Ti thin films and Ag:HAp + D3/Ti before and after irradiation was obtained using Image J software [52]. The 3D representation is depicted in Figure 16. The images presented in Figure 16 present the spatial distribution of C. albicans surviving cells (colored in red) along the horizontal (coverage) and the vertical (thickness) distributions on the surface of Ag:HAp/Ti thin films and Ag:HAp + D3/Ti before and after irradiation. The 3D CLSM images demonstrated that the development of C. albicans cells have been significantly inhibited in the presence of the tested samples after 
$24 \mathrm{~h}$ of incubation compared to the Ti disc used as control and that their inhibition was strongly correlated with the irradiation time and also with the presence of vitamin D.

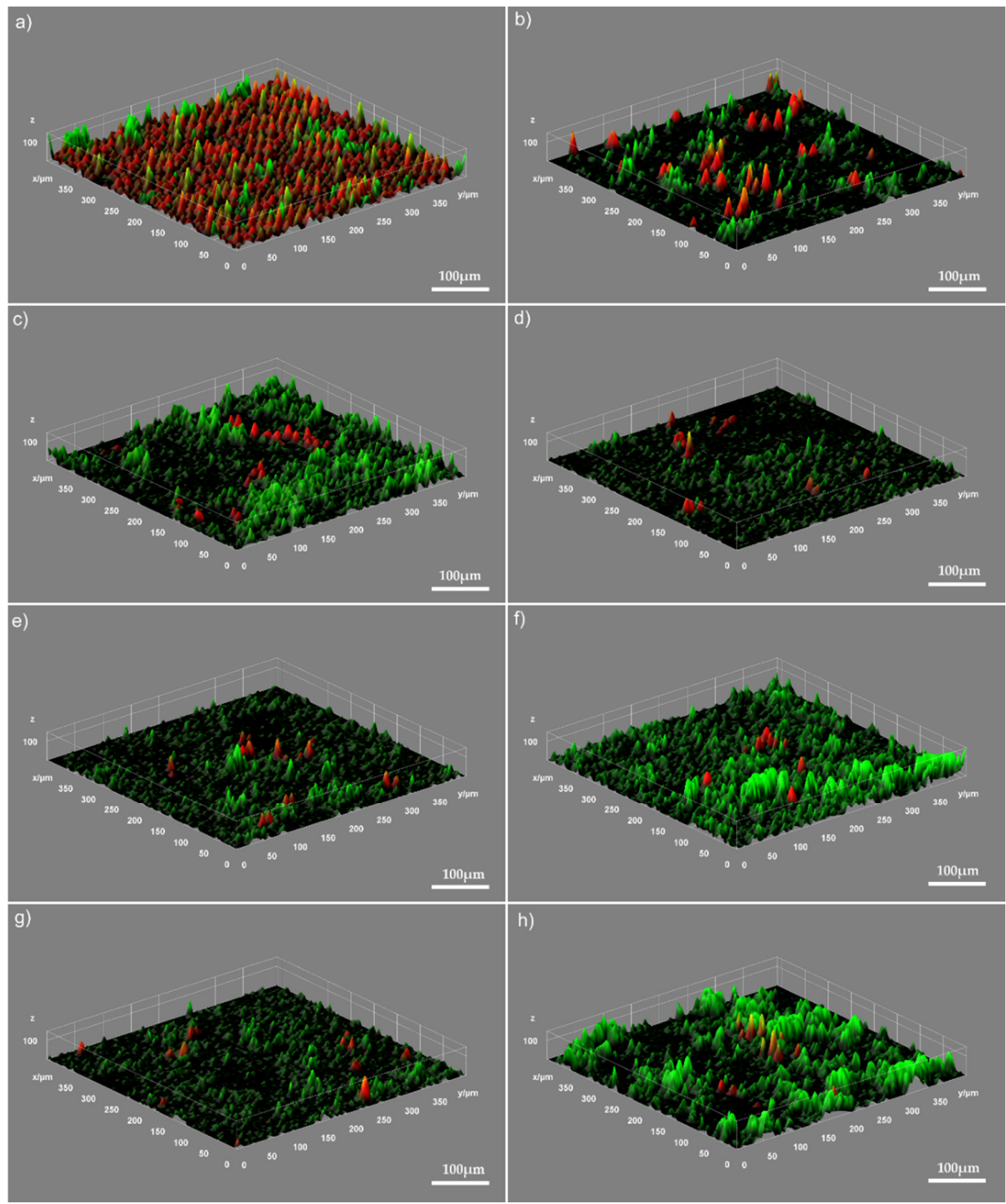

Figure 16. 3D representation of the CLSM images of Candida albicans ATCC 10,231 adhesion on Ti discs (a), Ag:HAp/Ti (b), Ag:HAp/Ti-140 (c), Ag:HAp/Ti-230 (d), Ag:HAp/Ti-410 (e), Ag:HAp/Ti-760 (f), Ag:HAp + D3/Ti (g), Ag:HAp + D3/Ti-230 (h) after 24 h of incubation.

The CLSM studies revealed that the best antifungal effect was obtained for the Ag:HAp $+\mathrm{D}_{3} /$ Ti-230 irradiated thin film samples, and that this could be attributed to both the addition of $\mathrm{D}_{3}$ and also to the UV irradiation. Moreover, in their studies, Matsumoto et al., Sebag et al., and Bunce et al. in their studies showed that vitamin $\mathrm{D}_{3}$ and its derivatives could be the key factor in exhibiting growth-inhibitory activity in normal human keratinocytes and it is also responsible for the apoptosis of breast tumor cell lines and HL60 cells [53-55]. Moreover, the Benassi et al. demonstrated in their study that UVB, calcium, TGF/31, and 1,25-dihydroxyvitamin $\mathrm{D}_{3}\left(1,25-(\mathrm{OH})_{2} \mathrm{D}_{3}\right)$ are responsible for the induction of keratinocytes apoptosis in vitro [56]. More than that, as well as UV light, calcium is also known to induce apoptosis in cultured human keratinocytes [56,57]. Furthermore, calcium was also reported to cause apoptosis in other types of cells such as thymocytes and hepatocytes $[58,59]$. In addition, Rubin et al. presented in their study convincing evidence suggesting that various regulatory factors that have the ability to control the cell cycle are also tangled in the mechanisms involved in cell death [57]. In this 
context, our results also suggest that the presence of vitamin $\mathrm{D}_{3}$ in the samples as well as the UV irradiation of the samples had a strong influence on the antifungal properties of the thin films.

One of the most common yeast species involved in various types of infections is Candida albicans. One of the major problems raised by this species is its great ability to form biofilms, probably contributing to its high resistance rates to chlorhexidine, nystatin, amphotericin B, and fluconazole [60,61]. Thus, in order to reduce the activity of this fungus, and consequently the biofilm formation, the Ag nanoparticles or Ag-based compounds have been used with promising antifungal properties [60-64]. In their study Mallmann, E.J.J. et al. [60] showed that the antifungal activity against $C$. albicans of silver nanoparticles obtained by green synthesis was more pronounced than the antifungal activity of Amphotericin B (a well-known antifungal drug). Also, the antifungal activity against C. albicans yest of graphene oxide-silver nanocomposites has been demonstrated by Li C. et al. [62]. Moreover, there are studies that have proved that compounds obtained by mixing silver nanoparticles with antifungal drugs (Nystatin and Chlorhexidine digluconate) can remove the Candida biofilms [63]. Additionally, recent studies regarding the antibiofilm activity of Ag-decorated hydroxyapatite nanoparticles showed that the antifungal activity depends on solution concentration [64]. Despite the existing studies, the mechanisms responsible for the antimicrobial properties of various compounds are still uncertain and not well documented. Studies reported different results for various types of materials and coatings and the possible antimicrobial mechanisms involved seem to be dependent on to the physic-chemical parameters of the samples. Moreover, in the case of coatings there has been reported a strong correlation between the antimicrobial properties exhibited by the samples and the synergistic connection between its chemical constituents and the substrate itself $[65,66]$. Our investigation suggests that the antifungal mechanism of the investigated samples could be attributed to the generation of ROS which may degrade the fungal cells. Furthermore, the results suggested that the Ti disk did not present antifungal properties, therefore the antifungal properties are to be attributed entirely to the presence of silver in the composite coatings as well as to their interaction with the substrate. In addition, the data also revealed that the addition of vitamin D and the of UV irradiation have greatly contributed to the antifungal properties of the samples

The antifungal assays performed revealed that the Ag:HAp/Ti and Ag:Hap + D3/Tit thin films before and after irradiation could have a great potential to be used in medical applications, as antifungal surfaces.

The cytotoxicity of the Ag:HAp/Ti and Ag:HAp+D3/Ti thin films before and after UV irradiation were investigated using the remarkably durable and prolific cell line and also the first immortal human cell line (HeLa cells [67]. The HeLa cells were incubated for $24 \mathrm{~h}$ with non-irradiated and irradiated Ag:HAp/Ti and Ag:HAp + D3/Ti thin films The morphology of the HeLa cells after $24 \mathrm{~h}$ of incubation with the thin films assessed by microscopic visualization is depicted in Figure 17.

The results of the fluorescence microscopy revealed that the HeLa cells incubated for $24 \mathrm{~h}$ with the samples did not suffered any significant changes in comparison with the number and morphology of the control cells. The maintaining of a viable status was confirmed by the trypan blue exclusion test. These results are in agreement with previous reported results regarding the toxicity of silver doped hydroxyapatite composites powders, suspensions and coatings [68-70]. Furthermore, the results have emphasized that the all the tested thin films exhibited an insignificant level of cytotoxicity against HeLa cell development after $24 \mathrm{~h}$ of incubation. The study also demonstrated that the thin films based on Ag:HAp composites enhanced with vitamin D and irradiated showed no toxic effect against the HeLa cells. 


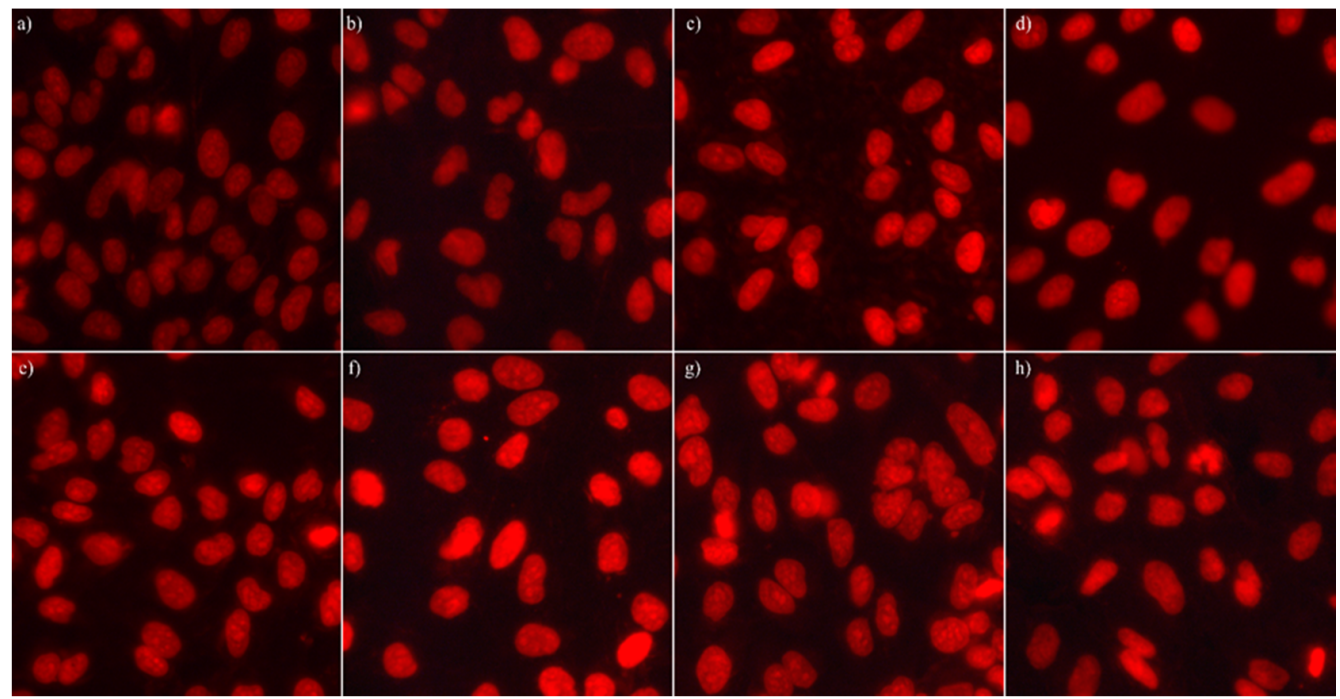

Figure 17. The morphology of the control HeLa cells (a) and of HeLa cells incubated with Ag:HAp/Ti (b), Ag:HAp/Ti-140 (c), Ag:HAp/Ti-230 (d),Ag:HAp/Ti-410 (e), Ag:HAp/Ti-760 (f), Ag:HAp + D3/Ti (g), Ag:HAp + D3/Ti-230 (h) after 24 h of incubation.

Complementary information regarding the toxicity of the Ag:HAp/Ti and Ag:HAp + D3/Ti thin films before and after UV irradiation was also obtained using human fetal osteoblasts (hFOB 1.19) cells. The coatings were incubated for $24 \mathrm{~h}$ with hFOB 1.19 cell cultures and their viability assessed using the MTT assay. Usually, short term in vitro studies that involves the cultivation of osteoblasts on different substrates are used to obtain information about the main reaction events between implants and cell tissue, and in order to identify and select the optimum substrates for the promotion of rapid healing and regeneration of the host bone. The MTT results of the viability of hFOB 1.19 cells incubated for $24 \mathrm{~h}$ with Ag:HAp/Ti and Ag:HAp + D3/Ti thin films before and after UV irradiation are presented in Figure 18.

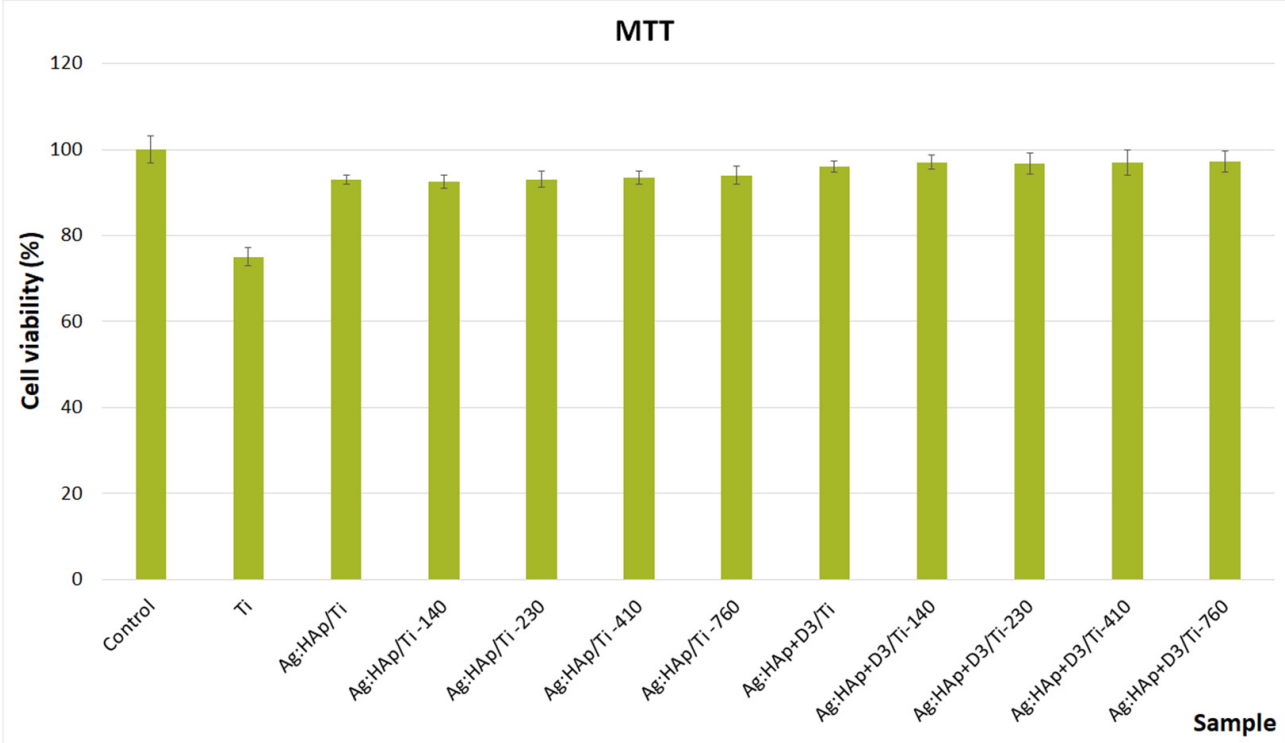

Figure 18. MTT assay for the viability of hFOB 1.19 cells incubated $24 \mathrm{~h}$ in the presence of Ti, Ag:HAp/Ti, Ag:HAp/Ti-140, Ag:HAp/Ti-230, Ag:HAp/Ti-410, Ag:HAp/Ti-760, Ag:HAp + D3/Ti, Ag:HAp+D3/Ti-140, Ag:HAp + D3/Ti-230. Ag:HAp + D3/Ti-410 and Ag:HAp+D3/Ti-760. The results are presented as means \pm standard error of the mean of three independent experiments. The data were statistically analyzed by using a $t$-Test: Paired Two Sample for Means and $p$ values, $p \leq 0.05$, were accepted as statistically significant. 
The experiments were performed in triplicate and the results data were presented as mean \pm SD. The statistical analysis was performed using a t-test: Paired two sample for means and all the $p$ calculated values were $p<0.05$. The results revealed that all the Ag:HAp/Ti and Ag:HAp + D3/Ti thin films before and after UV irradiation samples presented a cell viability above $93 \%$ compared with the control (100\%) after $24 \mathrm{~h}$ of incubation with the human fetal osteoblasts cells. In addition, for comparison purposes, the toxicity of an uncoated Ti disks was also assessed and the results revealed that the cell viability of the hFOB 1.19 incubated for $24 \mathrm{~h}$ with the uncoated Ti disc was $75 \%$. The MTT assays indicated that all tested materials were cytocompatible. Furthermore, the results also emphasized that the cells incubated with the irradiated Ag:HAp + D3/Ti samples exhibited a cell viability above $96 \%$. These results are in good agreement with previous reported studies which have shown that titanium has a good biocompatibility and that combined with a highly biocompatible coating could enhance the adhesion and proliferation of cells on its surface. Moreover, some studies reported that Ti implant's surface roughness could be responsible for the osteoblast cells adhesion and proliferation [71-76].

Furthermore, the adhesion and proliferation of the hFOB 1.19 cells incubated for $24 \mathrm{~h}$ with the Ag:HAp/Ti and Ag:HAp + D3/Ti thin films before and after UV irradiation was also assessed using an inverted microscope. The morphology of the hFOB 1.19 cells incubated for $24 \mathrm{~h}$ with Ag:HAp/Ti and Ag:HAp + D3/Ti thin films before and after UV irradiation are depicted in Figure 19.

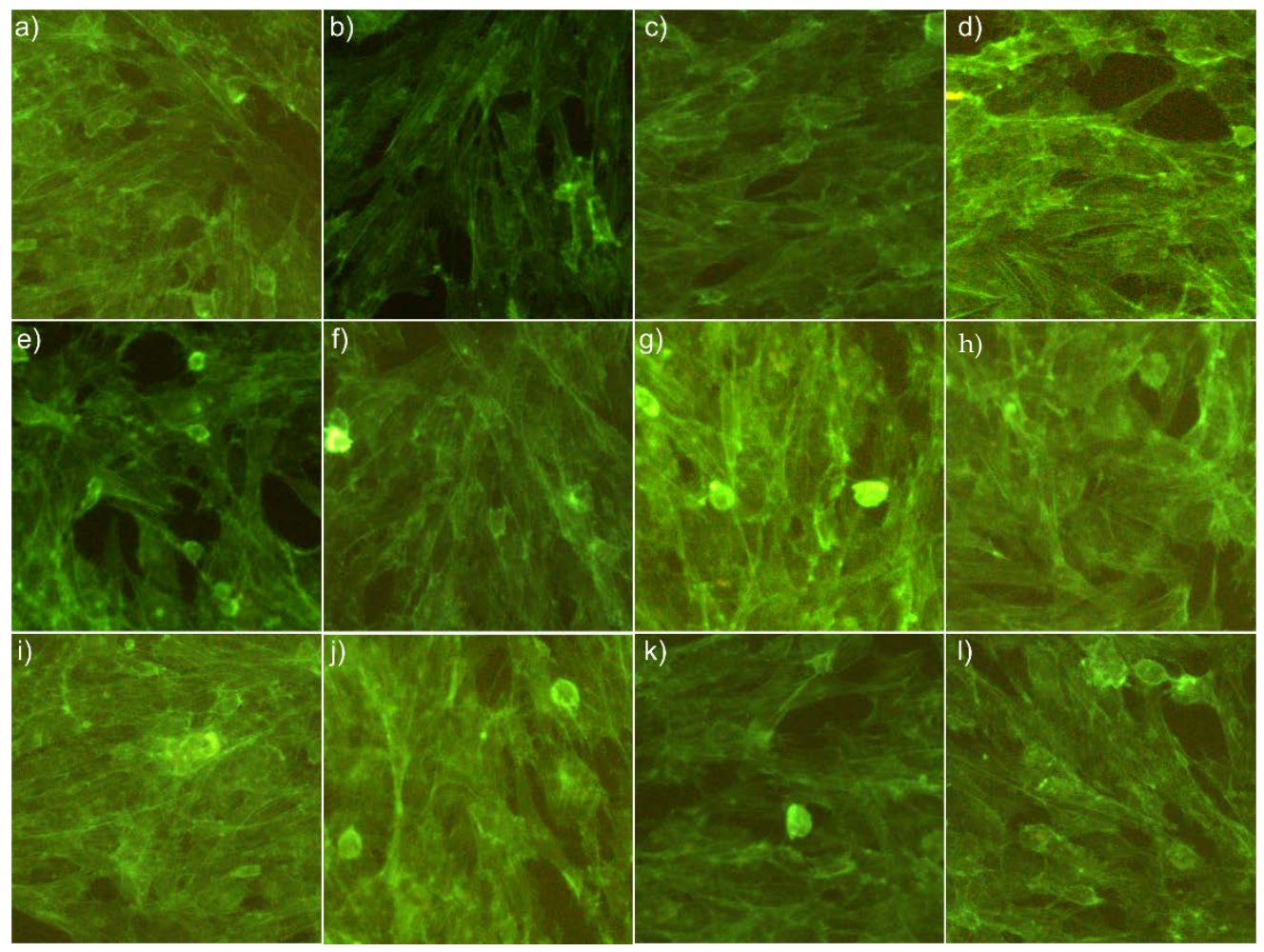

Figure 19. The morphology of the control hFOB 1.19 cells (a) and of hFOB 1.19 cells incubated with Ti (b), Ag:HAp/Ti (c), Ag:HAp/Ti-140 (d), Ag:HAp/Ti-230 (e),Ag:HAp/Ti-410 (f), Ag:HAp/Ti-760 (g), Ag:HAp + D3/Ti (h), Ag:HAp + D3/Ti-140 (i), Ag:HAp+D3/Ti-230 (j), Ag:HAp + D3/Ti-410 (k) and Ag:HAp + D3/Ti-760 (l) after $24 \mathrm{~h}$ of incubation.

The images of the hFOB 1.19 cells incubated with Ag:HAp/Ti and Ag:Hap + D3/Ti thin films before and after UV irradiation for $24 \mathrm{~h}$ emphasized that the hFOB 1.19 cells exhibited a normal morphology and also revealed that the coatings did not induce any significant changes in the hFOB 1.19 cells. The observations made by microscopic visualization of the cells incubated for $24 \mathrm{~h}$ with the Ag:HAp/Ti and Ag:Hap + D3/Ti thin films 
before and after UV irradiation are in good agreement with the quantitative MTT results of the in vitro assay, and evidenced that both all the investigated thin films presents a good biocompatibility and could be suitable for being further employed in the development of biomedical devices.

According to Ashish Yadav [77] the biological medium does not cause major corrosion of titanium and its alloy. On the other hand, previous studies [30-32,78] reported that the UV irradiation of the titanium or titanium alloys lead to a significant increase of the surface hydrophilicity and biological properties. Also, a similar behavior was noticed in the case of HAp disk [78]. Moreover, according to H. Nishikawa [30] the UV irradiation of the HAp surface could induce the formation of active radical species.

\section{Conclusions}

By this study we show for the first time the influence of UV irradiation on surfaces coated with a thin layer of silver doped hydroxyapatite (Ag:HAp) and silver doped hydroxyapatite and vitamin D3 (Ag:HAp + D3). Thus, the effects of UV irradiation on thin films (Ag:HAp and Ag:HAp + D3 on Ti) that could be used as possible antimicrobial coatings of medical devices or other medically related surfaces were highlighted. The antifungal studies have emphasized that all the tested samples exhibited an antifungal effect against Candida albicans ATCC 10231. Moreover, the results demonstrated that the antifungal effect of the samples is correlated with the incubation time. Furthermore, the stimulatory effect of the UV irradiation on the antifungal properties of the thin films was highlighted. In addition, the results also suggested that the antifungal properties are influenced by the irradiation time. The cytotoxicity assay results highlighted that all tested thin films exhibited an insignificant level of cytotoxicity against HeLa cell development after $24 \mathrm{~h}$ of incubation and did not induced any relevant morphology changes in HeLa cells. Furthermore, the cytotoxicity assays on human osteoblast hFOB 1.19 cells also revealed that the thin films did not induced notable morphological changes after $24 \mathrm{~h}$ of incubation. Moreover, the quantitative MTT assay evidenced that the hFOB 1.19 cells incubated with Ag:HAp and Ag:HAp + D3 thin films before and after irradiation presented high cell viability (above 92\%). These findings suggest that UV irradiation could be used not only for decontamination but also for improving the antifungal properties of silver based thin films and, together with vitamin D enhancement, could lead to the development of novel antifungal surfaces, suitable for various biomedical applications.

Author Contributions: Conceptualization, D.P., R.V.G., S.L.I., C.C.N., and M.C.C.; Methodology, D.P., R.V.G., S.L.I., C.C.N., S.C.C., M.M., M.L.B., A.C., R.T., G.P., G.A.S., R.H., C.B., I.C.M., and M.C.C.; Software, D.P., S.L.I., C.C.N.; Validation D.P., R.V.G., S.L.I., C.C.N., S.C.C., M.M., M.L.B., A.C., R.T., G.P., G.A.S., R.H., C.B., I.C.M., A.G., and M.C.C.; Formal Analysis D.P., S.L.I., C.C.N., S.C.C., A.C., R.T., R.H., C.B., I.C.M., A.G. and M.C.C.; Investigation, D.P., R.V.G., S.L.I., C.C.N., S.C.C., M.M., M.L.B., A.C., R.T., G.P., G.A.S., R.H., L.D.D., C.B., I.C.M., A.G., and M.C.C.; Resources, D.P., and M.C.C.; Data Curation, D.P., S.L.I., C.C.N., S.C.C., A.G., and M.C.C.; Writing-Original Draft Preparation, D.P., S.L.I., C.C.N., and M.C.C.; Writing-Review and Editing, D.P., S.L.I., C.C.N., S.C.C., R.V.G., and M.C.C.; Visualization D.P., S.L.I., C.C.N. and M.C.C.; Supervision, D.P., S.L.I., C.C.N., S.C.C., and M.C.C.; Project Administration, D.P., S.L.I., and M.C.C.; Funding Acquisition, D.P., and M.C.C. All authors have read and agreed to the published version of the manuscript.

Funding: This research was partially funded by the Romanian Ministry of Research and Innovation with the grants PN-III-P1-1.2-PCCDI-2017-0629/contract no. 43PCCDI/2018 and PN-III-P1-1.2PCCDI-2017-0134, contract No. 23PCCDI/2018

Institutional Review Board Statement: Not applicable.

Informed Consent Statement: Not applicable.

Data Availability Statement: Data is contained within the article.

Acknowledgments: The authors would like to thank Lucian Trupina for the AFM measurements.

Conflicts of Interest: The authors declare no conflict of interest. 


\section{References}

1. Dorozhkin, S.V. Bioceramics of calcium orthophosphates. Biomaterials 2010, 31, 1465-1485. [CrossRef] [PubMed]

2. Hontsu, S.; Matsumoto, T.; Ishii, J.; Nakamori, M.; Tabata, H.; Kawai, T. Electrical properties of hydroxyapatite thin films grown by pulsed laser deposition. Thin Solid Film. 1997, 295, 214-217. [CrossRef]

3. Predoi, D.; Popa, C.L.; Predoi, M.V. Ultrasound studies on magnetic fluids based on maghemite nanoparticles. Polym. Eng. Sci. 2017, 57, 485-490. [CrossRef]

4. Predoi, D.; Iconaru, S.L.; Predoi, M.V.; Motelica-Heino, M. Removal and oxidation of As(III) from water using iron oxide coated ctab as adsorbent. Polymers 2020, 12, 1687. [CrossRef]

5. Surmenev, R.A. A review of plasma-assisted methods for calcium phosphate-based coating fabrication. Surf. Coat. Technol. 2012, 206, 2035-2056. [CrossRef]

6. Predoi, D.; Iconaru, S.L.; Predoi, M.V. Dextran-coated zinc-doped hydroxyapatite for biomedical applications. Polymers 2019, 11, 886. [CrossRef]

7. Ciobanu, S.C.; Iconaru, S.L.; Predoi, D.; Prodan, A.M.; Predoi, M.V. Physico-chemical properties and in vitro antifungal evaluation of samarium doped hydroxyapatite coatings. Coatings 2020, 10, 827. [CrossRef]

8. Iconaru, S.L.; Motelica-Heino, M.; Guegan, R.; Predoi, M.V.; Prodan, A.M.; Predoi, D. Removal of zinc ions using hydroxyapatite and study of ultrasound behavior of aqueous media. Materials 2018, 11, 1350. [CrossRef]

9. Evis, Z.; Webster, T.J. Nanosize hydroxyapatite: Doping with various ions. Adv. Appl. Ceram. 2011, 110, 311-321. [CrossRef]

10. Predoi, D.; Predoi, M.V.; Iconaru, S.L.; Ech Cherif El Kettani, M.; Leduc, D.; Prodan, A.M. Ultrasonic measurements on $\beta$ cyclodextrin/hydroxyapatite composites for potential water depollution. Materials 2017, 10, 681. [CrossRef]

11. Predoi, D.; Iconaru, S.L.; Predoi, M.V.; Groza, A.; Gaiaschi, S.; Rokosz, K.; Raaen, S.; Negrila, C.C.; Prodan, A.-M.; Costescu, A.; et al. Development of cerium-doped hydroxyapatite coatings with antimicrobial properties for biomedical applications. Coatings 2020, 10, 516. [CrossRef]

12. Kittler, S.; Greulich, C.; Diendorf, J.; Koler, M.; Epple, M. Toxicity of silver nanoparticles increases during storage because of slow dissolution under release of silver ions. Chem. Mater. 2010, 22, 4548-4554. [CrossRef]

13. Chernousova, S.; Epple, M. Silver as antibacterial agent: Ion, nanoparticle and metal. Angew. Chem. Int. Ed. 2013, 52, 1636-1653. [CrossRef]

14. Prodan, A.M.; Iconaru, S.L.; Predoi, M.V.; Predoi, D.; Motelica-Heino, M.; Turculet, C.S.; Beuran, M. Silver-doped hydroxyapatite thin layers obtained by sol-gel spin coating procedure. Coatings 2020, 10, 14. [CrossRef]

15. Belgheisi, G.; Haghbin Nazarpak, M.; Solati Hashjin, M. Bone tissue engineering electrospun scaffolds based on layered double hydroxides with the ability to release vitamin D3: Fabrication, characterization and in vitro study. Appl. Clay. Sci. 2020, 185, 105434. [CrossRef]

16. Sumathra, M.; Munusamy, M.A.; Alarfaj, A.A.; Rajan, M. Osteoblast response to Vitamin D3 loaded cellulose enriched hydroxyapatite Mesoporous silica nanoparticles composite. Biomed. Pharm. 2018, 103, 858-868. [CrossRef]

17. Borges, M.C.; Martini, L.A.; Rogero, M.M. Current perspectives on vitamin D, immune system, and chronic diseases. Nutrition 2011, 27, 399-404. [CrossRef]

18. Ambrożewicz, E.; Muszyńska, M.; Tokajuk, G.; Grynkiewicz, G.; Žarković, N.; Skrzydlewska, E. Beneficial Effects of Vitamins K and D3 on Redox Balance of Human Osteoblasts Cultured with Hydroxyapatite-Based Biomaterials. Cells 2019, 8, 325. [CrossRef]

19. Bronze-Uhle, E.S.; Dias, L.F.G.; Trino, L.D.; Matos, A.A.; de Oliveira, R.C.; Lisboa-Filho, P.N. Physicochemical bisphosphonate immobilization on titanium dioxide thin films surface by UV radiation for bio-application. Surf. Coat. Technol. 2019, 357, 36-47. [CrossRef]

20. Xu, J.L.; Khor, K.A. Chemical analysis of silica doped hydroxyapatite biomaterials consolidated by a spark plasma sintering method. J. Inorg. Biochem. 2007, 101, 187-195. [CrossRef]

21. Boyd, A.; Akay, M.; Meenan, B.J. Influence of target surface degradation on the properties of r.f. magnetron-sputtered calcium phosphate coatings. Surf. Interface Anal. 2003, 35, 188-198. [CrossRef]

22. Kačiulis, S.; Mattogno, G.; Pandolfi, L.; Cavalli, M.; Gnappi, G.; Montenero, A. XPS study of apatite-based coatings prepared by sol-gel technique. Appl. Surf. Sci. 1999, 151, 1-5. [CrossRef]

23. Lai, Y.; Zhuang, H.; Xie, K.; Gong, D.; Tang, Y.; Sun, L.; Lin, C.; Chen, Z. Fabrication of uniform Ag/TiO 2 nanotube array structures with enhanced photoelectrochemical performance. New J. Chem. 2010, 34, 1335-1340. [CrossRef]

24. Hammond, J.S.; Gaarenstroom, S.W.; Winograd, N. X-ray photoelectron spectroscopic studies of cadmium- and silver-oxygen surfaces. Anal. Chem. 1975, 47, 2193-2199. [CrossRef]

25. Akhavan, $\mathrm{O}$. Lasting antibacterial activities of $\mathrm{Ag}-\mathrm{TiO}_{2} / \mathrm{Ag} / \mathrm{a}-\mathrm{TiO}_{2}$ nanocomposite thin film photocatalysts under solar light irradiation. J. Colloid Interface Sci. 2009, 336, 117-124. [CrossRef]

26. Oh, Y.J.; Yoo, J.J.; Kim, Y.I.; Yoon, J.K.; Yoon, H.N.; Kim, J.H.; Park, S.B. Oxygen functional groups and electrochemical capacitive behavior of incompletely reduced graphene oxides as a thin-film electrode of supercapacitor. Electrochim. Acta 2014, 116, 118-128. [CrossRef]

27. Rouxhet, P.G.; Misselyn-Bauduin, A.M.; Ahimou, F.; Genet, M.J.; Adriaensen, Y.; Desille, T.; Bodson, P.; Deroanne, C. XPS analaysis of food products: Toward chemical functions and molecular compounds. Surf. Interface Anal. 2008, 40, 718-724. [CrossRef]

28. Rouxhet, P.G.; Genet, M.J. XPS analysis of bio-organic systems. Surf. Interface Anal. 2011, 43, 1453-1470. [CrossRef] 
29. Zhao, F.; Vrajitoarea, A.; Jiang, Q.; Han, X.; Chaudhary, A.; Welch, J.O.; Jackman, R.B. Graphene-Nanodiamond Heterostructures and their application to High Current Devices. Sci. Rep. 2015, 5, 13771. [CrossRef]

30. Nishikawa, H. Surface changes and radical formation on hydroxyapatite by UV irradiation for inducing photocatalytic activation. J. Mol. Catal. A Chem. 2003, 206, 331-338. [CrossRef]

31. Pashkuleva, I.; Marques, A.P.; Vaz, F.; Reis, R.L. Surface modification of starch based biomaterials by oxygen plasma or UVirradiation. J. Mater. Sci. Mater. Med. 2010, 21, 21-32. [CrossRef]

32. Brezavšček, M.; Fawzy, A.; Bächle, M.; Tuna, T.; Fischer, J.; Att, W. The effect of uv treatment on the osteoconductive capacity of zirconia-based materials. Materials 2016, 9, 958. [CrossRef] [PubMed]

33. Yasuda, K.; Okazaki, Y.; Abe, Y.; Tsuga, K. Effective UV/Ozone irradiation method for decontamination of hydroxyapatite surfaces. Heliyon 2017, 3, e00372. [CrossRef] [PubMed]

34. Tuna, T.; Wein, M.J.; Swain, M.; Fischer, J.; Att, W. Influence of ultraviolet photofunctionalization on the surface characteristics of zirconia-based dental implant materials. Dent. Mater. 2015, 312, e14-e24. [CrossRef] [PubMed]

35. Qiying, T.; Wang, Z.; Chen, G.; Cai, W.; Cao, P.; Zhang, C.; Wangwang, D.; Lu, X.; Luo, T.; Qu, X.; et al. Selective laser melting of CP-Ti to overcome the low cost and high performance trade-off. Addit. Manuf. 2020, 34, 101198. [CrossRef]

36. Wangwang, D.; Wang, Z.; Chen, G.; Cai, W.; Zhang, C.; Qiying, T.; Qu, X.; Qin, M. Oxidation behavior of low-cost CP-Ti powders for additive manufacturing via fluidization. Corros. Sci. 2021, 178, 109080. [CrossRef]

37. Fritz, W.J. Analysis of Rapid Degradation in High-Power (AlGa)As Laser Diodes. IEEE J. Quantum Electron. 1990, 26 , 68-74. [CrossRef]

38. Ciobanu, C.S.; Massuyeau, F.; Constantin, L.V.; Predoi, D. Structural and physical properties of antibacterial Ag-doped nanohydroxyapatite synthesized at $100{ }^{\circ} \mathrm{C}$. Nanoscale Res. Lett 2011, 6, 613. [CrossRef]

39. Predoi, D.; Iconaru, S.L.; Predoi, M.V.; Motelica-Heino, M.; Guegan, R.; Buton, N. Evaluation of antibacterial activity of zinc-doped hydroxyapatite colloids and dispersion stability using ultrasounds. Nanomaterials 2019, 9, 515. [CrossRef]

40. Groza, A.; Ciobanu, C.S.; Popa, C.L.; Iconaru, S.L.; Chapon, P.; Luculescu, C.; Ganciu, M.; Predoi, D. structural properties and antifungal activity against Candida albicans biofilm of different composite layers based on ag/zn doped hydroxyapatitepolydimethylsiloxanes. Polymers 2016, 8, 131. [CrossRef]

41. Predoi, D.; Popa, C.L.; Chapon, P.; Groza, A.; Iconaru, S.L. Evaluation of the antimicrobial activity of different antibiotics enhanced with silver-doped hydroxyapatite thin films. Materials 2016, 9, 778. [CrossRef]

42. Arumugam, S.K.; Sastry, T.P.; Sreedhar, B.; Mandal, A.B. One step synthesis of silver nanorods by autoreduction of aqueous silver ions with hydroxyapatite: An inorganic-inorganic hybrid nanocomposite. J. Biomed. Mater. Res. 2007, 80, 391-398. [CrossRef] [PubMed]

43. Heidari, A. Measurement the amount of Vitamin D2 (Ergocalciferol), Vitamin D3 (Cholecalciferol) and absorbable Calcium (Ca $\left.{ }^{2+}\right)$, Iron (II) $\left(\mathrm{Fe}^{2+}\right)$, Magnesium $\left(\mathrm{Mg}^{2+}\right)$, Phosphate $\left(\mathrm{PO}^{4-}\right)$ and $\mathrm{Zinc}\left(\mathrm{Zn}^{2+}\right)$ in apricot using high-performance liquid chromatography (HPLC) and spectroscopic techniques. J. Biom. Biostat. 2016, 7, 292. [CrossRef]

44. Thoke Sagar, B.; Sharma Yogesh, P.; Rawat Swati, S.; Nangude Satish, L. Formulation development \& evaluation of effervescent tablet of alendronate sodium with vitamin D3. J Drug Deliv. Ther. 2013, 3, 65-74. [CrossRef]

45. Sipsasa, N.V.; Kontoyiannis, D.P. Invasive fungal infections in patients with cancer in the intensive care unit. Int. J. Antimicrob. Agents 2012, 39, 464-471. [CrossRef] [PubMed]

46. Tobudic, S.; Kratzer, C.; Lassnigg, A.; Presterl, E. Antifungal susceptibility of Candida albicans in biofilms. Mycoses 2012, 55, 199-204. [CrossRef] [PubMed]

47. Jelínek, M.; Kocourek, T.; Jurek, K.; Remsa, J.; Mikšovský, J.; Weiserová, M.; Strnad, J.; Luxbacher, T. Antibacterial properties of Ag-doped hydroxyapatite layers prepared by PLD method. Appl. Phys. A 2010, 101, 615-620. [CrossRef]

48. Ciobanu, C.S.; Iconaru, S.L.; Le Coustumer, P.; Predoi, D. Vibrational investigations of silver-doped hydroxyapatite with antibacterial properties. J. Spectrosc. 2013, 2013, 471061. [CrossRef]

49. Stanic, V.; Janackovic, D.; Dimitrijevic, S.; Tanaskovic, S.B.; Mitric, M.; Pavlovic, M.S.; Krstic, A.; Jovanovic, D.; Raičević, S. Synthesis of antimicrobial monophase silver-doped hydroxyapatite nanopowders for bone tissue engineering. Appl. Surf. Sci. 2011, 257, 4510-4518. [CrossRef]

50. Holick, M.F. Sunlight and vitamin D for bone health and prevention of autoimmune diseases, cancers, and cardiovascular disease. Am. J. Clin. Nutr. 2004, 80, 1678S-1688S. [CrossRef]

51. Holick, M.F. Evolutionary biology and pathology of vitamin D. J. Nutr. Sci. Vitam. 1992, 38, 79-83. [CrossRef]

52. Image J Software. Available online: http://imagej.nih.gov/ij (accessed on 10 January 2018).

53. Matsumoto, K.; Hashimoto, K.; Nishida, Y.; Hashiro, M.; Yoshikawa, K. Growth-inhibitory effects of 1,25-dihydroxy vitamin $D_{3}$ on normal human keratinocytes cultured in serum-free medium. Biochem. Biophys. Res. Commun. 1990, 166, 916-923. [CrossRef]

54. Sebag, M.; Gulliver, W.; Kremer, R. Effects of 1,25-dihydroxyvitamin $\mathrm{D}_{3}$ and calcium on growth and differentiation and on $c-f o s$ and p53 gene express ion in normal human keratinocytes. J. Investig. Derm. 1994, 103, 323-329. [CrossRef] [PubMed]

55. Bunce, C.M.; Wallington, L.A.; Harrison, P.; Williams, G.R.; Brown, G. Treatment of HL60 cells with various combinations of retinoids and 1 alpha, 25 dihydroxyvitamin D3 results in differentiation towards neutrophils or monocytes or a failure to differentiate and apoptosis. Leukemia 1995, 9, 410-418. 
56. Benassi, L.; Ottani, D.; Fantini, F.; Marconi, A.; Chiodino, C.; Giannetti, A.; Pincelli, C. 1,25-dihydroxyvitamin D D $_{3}$ transforming growth factor beta1, calcium, and ultraviolet B radiation induce apoptosis in cultured human keratinocytes. J. Investig. Derm. 1997, 109, 276-282. [CrossRef] [PubMed]

57. Rubin, L.L.; Philpott, K.L.; Brooks, S.F. The cell cycle and cell death. Curr. Biol. 1993, 3, 391-394. [CrossRef]

58. McConkey, D.J.; Nicotera, P.; Orrcnius, S. Signalling and chromatin fragmentation in thymocyte apoptosis. Immunol. Rev. 1994, 142, 343-363. [CrossRef]

59. Jones, D.P.; McConkey, D.J.; Nicotera, P.; Orrenius, S. Calcium-activated DNA fragmentation in rat liver nuclei. J. Biol. Chem. 1989, 264, 6398-6403. [CrossRef]

60. Mallmann, E.J.; Cunha, F.A.; Castro, B.N.; Maciel, A.M.; Menezes, E.A.; Fechine, P.B. Antifungal activity of silver nanoparticles obtained by green synthesis. Rev. Inst. Med. Trop. Sao Paulo 2015, 57, 165-167. [CrossRef]

61. Chandra, J.; Mukherjee, P.K.; Leidich, S.D.; Faddoul, F.F.; Hoyer, L.L.; Douglas, L.J.; Ghannoum, M.A. Antifungal resistance of candidal biofilms formed on denture acrylic in vitro. J. Dent. Res. 2001, 80, 903-908. [CrossRef]

62. Li, C.; Wang, X.; Chen, F.; Zhang, C.; Zhi, X.; Wang, K.; Cui, D. The antifungal activity of graphene oxide-silver nanocomposites. Biomaterials 2013, 34, 3882-3890. [CrossRef]

63. Monteiro, D.R.; Silva, S.; Negri, M.; Gorup, L.F.; de Camargo, E.R.; Oliveira, R.; Barbosa, D.B.; Henriques, M. Antifungal activity of silver nanoparticles in combination with nystatin and chlorhexidine digluconate against Candida albicans and Candida glabrata biofilms. Mycoses 2013, 56, 672-680. [CrossRef] [PubMed]

64. Zamperini, C.; Andre, R.S.; Longo, V.M.; Mima, E.G.; Vergani, C.; Machado, A.; Varela, J.; Longo, E. Antifungal applications of Ag-decorated hydroxyapatite nanoparticles. J. Nanomater. 2013, 2013, 7. [CrossRef]

65. Buergers, R.; Rosentritt, M.; Handel, G. Bacterial adhesion of Streptococcus mutans to provisional fixed prosthodontic material. J. Prosthet. Dent. 2007, 98, 461-469. [CrossRef]

66. Kim, K.J.; Sung, W.S.; Suh, B.K.; Moon, S.K.; Choi, J.S.; Kim, J.G.; Lee, D.G. Antifungal activity and mode of action of silver nano-particles on Candida albicans. Biometals 2009, 22, 235-242. [CrossRef] [PubMed]

67. Rahbari, R.; Sheahan, T.; Modes, V.; Collier, P.; Macfarlane, C.; Badge, R.M. A novel L1 retrotransposon marker for HeLa cell line identification. Biotechniques 2009, 46, 277-284. [CrossRef] [PubMed]

68. Predoi, D.; Iconaru, S.L.; Predoi, M.V. Bioceramic Layers with Antifungal Properties. Coatings 2018, 8, 276. [CrossRef]

69. Jelinek, M.; Kocourek, J.T.; Remsa, J.; Weiserová, M.; Jurek, K.; Mikšovský, J.; Strnad, J.; Galandáková, A.; Ulrichová, J. Antibacterial, cytotoxicity and physical properties of laser-Silver doped hydroxyapatite layers. Mater. Sci. Eng. C 2013, 33, 1242-1246. [CrossRef]

70. Jelínek, M.; Weiserová, M.; Kocourek, T.; Zezulová, M.; Strnad, J. Biomedical properties of laser prepared silver-doped hydroxyapatite. Laser Phys. 2011, 21, 1265-1269. [CrossRef]

71. Sola-Ruiz, M.F.; Perez-Martinez, C.; Labaig-Rueda, C.; Carda, C.; Martín De Llano, J.J. Behavior of Human Osteoblast Cells Cultured on Titanium Discs in Relation to Surface Roughness and Presence of Melatonin. Int. J. Mol. Sci. 2017, 18, 823. [CrossRef]

72. Gittens, R.A.; McLachlan, T.; Olivares-Navarrete, R.; Cai, Y.; Berner, S.; Tannenbaum, R.; Schwartz, Z.; Sandhage, K.H.; Boyan, B.D. The effects of combined micron-/submicron-scale surface roughness and nanoscale features on cell proliferation and differentiation. Biomaterials 2011, 32, 3395-3403. [CrossRef]

73. Balloni, S.; Calvi, E.M.; Damiani, F.; Bistoni, G.; Calvitti, M.; Locci, P.; Becchetti, E.; Marinucci, L. Effects of titanium surface roughness on mesenchymal stem cell commitment and differentiation signaling. Int. J. Oral Maxillofac. Implant. 2009, 24, 627-635.

74. Kim, C.-S.; Sohn, S.-H.; Jeon, S.-K.; Kim, K.-N.; Ryu, J.-J.; Kim, M.-K. Effect of various implant coatings on biological responses in MG63 using cDNA microarray. J. Oral Rehabil. 2006, 33, 368-379. [CrossRef] [PubMed]

75. Lee, J.J.; Rouhfar, L.; Beirne, O.R. Survival of hydroxyapatite-coated implants: A meta-analytic review. J. Oral Maxillofac. Surg. 2000, 58, 1372-1379. [CrossRef] [PubMed]

76. Olivares-Navarrete, R.; Gittens, R.A.; Schneider, J.M.; Hyzy, S.L.; Haithcock, D.A.; Ullrich, P.F.; Schwartz, Z.; Boyan, B.D. Osteoblasts exhibit a more differentiated phenotype and increased bone morphogenetic protein production on titanium alloy substrates than on poly-ether-ether-ketone. Spine J. 2012, 12, 265-272. [CrossRef] [PubMed]

77. Yadav, A.; Yadav, R.; Gupta, A.; Baranwal, A.; Bhatnagar, A.; Singh, V. Effect of ultraviolet irradiation on the osseointegration of a titanium alloy with bone. Contemp. Clin. Dent. 2017, 8, 571-578. [CrossRef] [PubMed]

78. Kaneko, S.; Yamamoto, Y.; Wada, K.; Kumagai, G.; Harada, Y.; Yamauchi, R.; Ishibashi, Y. Ultraviolet irradiation improves the hydrophilicity and osteo-conduction of hydroxyapatite. Orthop. Surg. Res. 2020, 15, 425. [CrossRef] 